In C.M. Brown \& P. Hagoort (Eds.)

Neurocognition of Language.

Oxford: Oxford University Press (1999) 


\section{The neurocognition of syntactic processing}

Peter Hagoort, Colin M. Brown, and Lee Osterhout

\section{1 introduction}

Syntax matters. This is illustrated by the fact that we can parse sentences without understanding their meaning, as in I knuster with my knesidon and strinpel like a criks (after Cees Buddingh, Het mes op de gorgel, 1960). Although we don't know what kntster and knesidon mean, we can still determine that the former must be a verb and the latter a noun. Sentences made up (in part) of word-like elements with a legal orthographic form but bereft of meaning are often easy to structure in terms of grammatical categories such as subject, direct object, etc. It thus should come as no surprise that syntactic cues are seen as an integral part of language processing. That is, it is a nearly universally accepted notion in current models of the production and interpretation of multiword utterances that constraints on how words can be structurally combined in sentences are immediately taken into consideration during speaking and listening/reading. These constraints operate next to qualitatively distinct constraints on the combination of word meanings, on the grouping of words into phonological phrases, and on their referential binding into a mental model. Together, these constraints solve the 'binding problem' for language, or in other words how speakers and writers, listeners and readers bind single-word information into multiword utterances and complex messages.

Despite considerable agreement on the types of constraints that are effective during the formulation and the interpretation of sentences, exactly how these constraints are implemented in the overall design of the sentence processing machinery is still an issue of intense debate in psycholinguistics. Central in this debate is to what extent the operation of syntactic cues can be sealed off from the influence of other types of constraints during the on-line interpretution or formulation process. This focus on the contribution of syntactic cues is presumably a consequence of the "syntactocentrism' of the Chonskian tradition within linguistics (Jackendoff 1997). As a result, in research on sentence-level processing the role of syntactic constraints has been at centre stage 
over at least the last two decades. This holds alike for neurolinguistic patient studies, recent brain-imaging studies, and psycholinguistic studies of sentence processing. Since this chapter discusses language processing beyond the single-word level, ils focus is therefore on syntax.

A complete theory of the neurocognition of syntax has to specify how grammatical encoding (speaking) and parsing (comprehension) are organized and embedded in the overall process of speaking and listening/reading. However, this is not enough. In addition we need to specify which neural mechanisms enable and instantiatie the combinatorial apparatus that is so central to natural tanguige. Knowledge about the neural basis of syntax will furthermore help to sharpen our understinding of syntactic processing. At the same time, we need a sufficiently detailed analysis of syntactic processing to target our research on its neural underpinnings. Although it is early days for a truly cognitive nemroscience of syntax, it is possible to sketch some of its ingredients and the currently most relevant results. This is the task we set ourselves in this chapter.

First we will present the ingredients of a cognitive architecture of syntactic processing, with special attention to issues that are of relevance for studies on the neural architecture of syntax. Then we will discuss recent electrophysiological insights into syntactic processing, followed by a review of the relevant lesion literature and of recent brain-imaging (haemodynamic) studies with a focus on sentence processing. In the final section of this chapter we evaluate the current state of knowledge on the neurocognition of syntax and conclude with a few suggestions for future research. Since most sentence processing research investigates comprehension (reading listening), and not production (speaking), we will mainly focus our discussion on comprehension.

\subsection{Issues in syntactic processing}

Each word form (lexeme) in the mental lexicon is associated with syntuctic word information (Levelt 1989, and this volume, Chapter 4; Roelof' 1992, 1993). This latter type of information is teferred to as lenuma information. Lemmas specify the syntactic properties of words, such as their word class (Noun, Verb, Adverb, Adjective, Picposition, etc.). For nouns in gender-marked languages their grammatical gender is specified as well (e.g. horse in French has masculine gender, in Ditch it has neuter gender). Verb lemmas contain information on syntactic frames (the argument structures), and on the thematic roies of the syntactic arguments (the themalic structure). For instance the lemma for the verb donate specifies that it requires a subject-NP, and a direct object-NP, with the optional addition of an indirect object-PP (e.g. Johm (subject-NP) donates a book (direct object-NP) to the lihrury (optional indirect objectPP). In addition, the mapping of this syntactic frame onto the thenatic roles is specified. For clonate the stbject is the actor, the direct object the theme, and the indirect object the goal or benefuctive of the action expressed by the predicate ffor more detilis see Chapter 3 and the chapters in Section 2 of this volume).

In speaking. ternmas are activated on the basis of the preverbal messige that the speaker intends to express. Here lemmas are the intermediary butween the preterbit 
messige and the articulation of an utterance. In listening and reading, the direction of processing is the reverse. Now lemma activation occurs on the basis of word form information. Despite this difference in the sources of lemma activation between production and comprehension, in both cases lemmas are crucial as triggers for further structure-building operations. These structure-building operations cluster words in syntactic phrases and assign these phrases their grammatical roles. An example of this clustering is given with a labelled bracketing notation in (1):

(1) [s [NP The little old lady] [vP bit [NP the gigantic pitbuil terrier]]]

It is generally assumed that both in production and comprehension structure building is done incrementally and with no or very short delays relative to lenma activation. In speaking, the syntactic fragments that come with the lemmas are assembled into larger structures, a process labelled unification (Kempen 1997; Levelt, this volume). Through the incremental unification process the syntactic structure of the complete utferance is determined. In this way the speaker generates an abstract surface structure (grammatical encoding) that guides the retrieval of the sound patterns (morpho-phonological encoding) necessary for determining the articulatory gestures resulting in overt speech. A similar incrementality is characteristic for comprehension. Once a fermma is retrieved on the basis of the spoken or written input, the relevant lemma information is immediately inserted into the constituent structure built for the preceding lemmas. This on-Jine assignment of structure to an incoming string of written or spoken words is referred to as parsing. A crucial aspect of comprehension is that the sentence structure is often locally underdetermined (syntactic ambiguity). Since at many points in the input more than one structural assignment is possible, the incrementat nature of structure building can result in a garden path, as is clear in the famous example of Bever (1970):

(2) The horse raced past the barn fell.

Sentence processing theories differ with respect to how mach of the overall sentence structute is assumed to be present as precompiled syntactic tragments in memory (i.e. the lexicon). In some proposils (e.g. Kempen 1997; MacDonald et at. I994) substantial picces of syntactic structure are lexically specified. The overall sentente structure cals then be seen to result from inking the syntactic fragments that are activated on the basis of lenma inpat. Other proposals te.g. Frazier 1987; Frazier and Clifton 1996: Pritchett 1992) assame that lemmas trigger structure-building operations in some form of procedural memory, and that these operations assemble phrase structures on the fly.

Despite these differences, there is again almost universal agreement that usually the whole sentence structure cannot be retrieved from memory, but has to be buil out of snlaller fragments. This then requires thit lemmas and syntactic fragments or partial products of structure buikling are kept active until all the relevant syntactic slots are fijled. Computational resources are needed to run this process to its completion. That is, the lemma information and syntactic fragments or intermediate structure-building products have to be instantiated and integrated in working memory. Both storage and processing in working memory tax the available umount of computational resources 
(Caplan and Waters, 1999; Gibson 1998; Just and Carpenter 1992). Diffetences in the amount of computational resources needed for structure building might explain why some sentences are harder to understand or need more processing time than others. For instance, across comprehension studies using a variety of dependent meusures (e.g. reading times, lexical decision latencies, response accuracy to probe questions) it is consistently found that object-extracted retative clauses (3a) are more complex than subject-extracted relative clatses (3b) (e.g. Gibson 1998; King and Jus1 1991; Waters et al. 1987).

(3) a. The reporter who the senator attacked admitted the error.

b. The reporter who attacked the senator admitted the error.

Similarly, sentences with centre-embedded structures (4a) are notoriously harder to process than sentences with right-branching structures (4b).

(4) a. The juice that the child spilled stained the rug.

b. The child spilled the juice that stained the rug.

Despite different proposals about the relation between structural complexity and computational resources (see Gibson 1998, for an overview), a tight relationship seems to exist between structure-building operations and the resources that are necessiry to support them. However, often the notion of computational resources licks sufficient precision to determine in more detail how limitations in these resources aftect grimmatical encoding and parsing.

Apart from the overall agreement on the major components of grammatical encoding and parsing, there are also unresolved issues that have to be kept in mind when studying the neural architecture of syntactic processing. We will discuss the most relevant ones. Given the current bias of the field, all points relate to parsing, and only two (see 9.2.1 and 9.2.3) also relate to grammatical encoding.

\subsubsection{A single versus a dual processor for grammatical encoding and parsing}

Although the syntactic constraints are not different in speaking and listening/teitding, nevertheless prinufoctic grammaticat encoding is quite different fron parsing. For one, word order is given in parsing, bat has to be computed in grammatical encoding. Furthermore, structural indeterminacy has to be faced contintously in parsing, whereas in the formulation process structure is incrementally detsrmined by the preverbal message, the lemma input, and the syntactic constraints.

Despite the seemingly relevant differences between parsing and grammatical encoding, there are arguments in favour of a single processor account, and architectures have been proposed that handle both grammatical encoding and parsing in a unified manner (Kempen 1999; Vosse and Kempen 1999). One argument is parsimony; it is more parsinonious to assume that the lexieat buitding blocks for syntactic processing such as lemmas and, it present, syntactic fratements are not doubly, but singly represented. Moreover, intutitively there sems to be a fairly strong correlation between sentence structures that speakers find hard to produce and sentence structures that 
listeners find difficult to understand. The reason why more complex structures are often less frequent than more simple constructions might be exactly because they seem to cause the same problem for the formulator as for the parser. Finally, witl a few exceptions, the overwhelming majority of agrammatic aphasics show strong correlittions between impairments in grammatical encoding and parsing.

However, the presence of those exceptional cases of patients with a syntactic production deficit without a concomitant comprehension impairment (Kolk et al. 1985; Miceli at al. 1983; Nespoulous et al. 1992) can be taken as an argument against a single processor account. Rare as these cases night be, the fact that impitirments in grammatical encoding can be dissociated from impairments in parsing. suggests that there is no necessary connection between syntactic processing in production and comprehension.

In short, whether the processing machinery for grammatical encodjng and parsing is the sinne or different, is still an open issue. Although this issue is obviously relevant for research on the neural architecture of syntactic processing, it has hardly been explicitly addressed.

\subsubsection{A modalify-specific parser versus a modality-independent parser}

One of the clear differences between reading and listening to speech is the prosodic information that is encoded in the speech signal but not in writing. The phonological and intonational phrasings of an utterance contribute to the assignment of a syntactic structure to a sentence. Given the contribution of speech-specific information to parsing, we cannot exclude the possibility that the parsing operations in listening are qualitatively different from the ones in reading. This would imply modality-specific parsers for reading and listening. Alternatively, the parsing operations could be modality-independeni, with an extra source of information that the general parser works with in the cuse of speech. This latter view is explicitly or implicitly assumed in most models of language comprehension (see Cutler and Clifton, Chapter 5 this volume, for more detail).

\subsubsection{General versus dedicated working-memory support for structure buliding}

As we discussed tbove, syntactic operations require working-memory resources. There is an ongoing debate in the literature with respect to the specificity of these resources. Just and Carpenter and their colleagues (e.g. Just and Carpenter 1992; Just (t $a / .199(a)$ have advocated the view that all aspects of language processing are supported by a common general verbal working memory. Caplan and Waters fe.g. Caplan and Waters 1996, in press: Waters and Caplan 1996) claim that parsing is subserved by a dedieviled working-memory system. A major retson for postulating it sejarate parsing huffer comes from neuropsychological data. Patients have been dexcribed who show a co-oceurrence of a severe reduction in their working-memory capacity and a preservation of the capacity to formulate and/or tnderstand syntacticilly complex sentences (e.g. Butterworth et al. 1986; Caphan and Waters 1990, 
in press: Martin 1993; Waters at $a l$. 1991). To date the issue of a general versus a dedicated resource systen for parsing has not yet been settled.

\subsubsection{Structural precedence versus all cues are equal}

One of the central issues in research on sentence-level comprehension is what sources of information contribute to the structure that is initially assigned to an incoming string of words. As was discussed above, at many points in a sentence its structure is underdetermined. That is, more than one structure can be assigned on the basis of patticular lemma information, as is clear in the following example:

(5) The teacher sees the boy and the girl...

After reading (or hearing) ginl the sentence can continue in two structurally different ways, affecting the structural role that has to be assigned to the noun girl, as is exemplified in (6a) and (6b):

(6) a. [s The teacher [vp sees [NP the boy and the girl] dtring their holiday]]

b. [s The teacher [vr sees the boy]] and [s the girl [vp sees the teacher]]

In (6a) the string the bor and the gir / forms the object-NP of the sentence. In (6b) the girl is not part of the object-NP, but it is the subject of the second clause. Which structure has to be assigned becomes cleir oniy after the noun girl. However, there is pretty solid evidence that even in the absence of sufficient information for deternining the structure, there will be a preference when encountering the noun girl to assign it one structural role rather than the other. In this particular case the structure of (6a) is preferred over the one in (6b), presumably on the basis of differences in syntactic complexity (Frazier 1987; Frazier and Rayner 1982) or differences in frequency of occurrence of the alternative structures (Mitchell 1994; Mitchell et al. 1995).

The bias for one structure over the other can be modulated or overwritten by the preceding discourse or by lexical information in the sentence context, as is clear in (7):

(7) The teacher buys the ticket and the giri...

In this sentence the context induces a strong expectancy for a structure where gir/ starts a second clause. This is due to the semantics of the verb buy which goes together easily with an inanimate object but not so easily with an animate object. However, some sentence-processing models claim that independent of this type of contextual information, in first instance a stracture is assigned exclusively on the basis of structurat principles, which is then passed on to the semantic interpreter for evaluation (tef. Frazier 1987). The semantic interpreter can reject this structure, resuiting in the subsequent assignment of an alternative strkctural option. Other models, in contrilst, claim that there is no such priority for purely structural information in computing a syntactic structure, but that atl relevant sources of information atre immediately taken into consideration when assigning syntactic stracture to an incoming string of words (e.g. Garnsey et al. 1997; Tanenhaus and Trueswell 1995). Over the last few years there has been increasing evidence in favour of this latter class of so-called constraint-based 
parsing models. That is, pragmatic, semantic, and syntactic information all seem to play an immediate role in determining the structure of an utterance, at least in cases of syntactic ambiguity.

\subsubsection{Structural output versus semantic output}

So far, we have tacitly assumed that both in language production and in language comprehension there is a processing level that generates a syntactic output. In models of speaking, this assumption is widely accepted (cf. Bock 1990, 1995; Bock and Levelt 1994; Dell 1986; Gartett 1980). To produce grammatically well-formed utterances the speaker has to order the lemmas and specify their grammatical functions in accordance with the syntactic constraints of the language. The abstract surface structure thus generated is the frame for the insertion of morpho-phonological information (see Levelt, Chapter 4 this volume). The situation is different in comprehension. In comprehension the listener or reader wants to derive the message of the speaker or the text. One can imagine that in this case all information is used and combined in a direct mapping of word information onto an overall interpretation, without an intermediate level of syntactic structure. This is exactly what some constraint-based models of sentence interpretation propose (cf. Bates and Goodman, 1997; Bates et al. 1982; McClelland ot al. 1989). In these models pragmatic, semantic, and syntactic cues all imnediately contribute to constrain the interpretation space of a given utterance and to settle it in a state of equilibrium that underlies the derived message. In the most parsimonious version of such a model all relevant cues are handled by a unified sentence processor that takes the lexical information as input and derives the interpretation by the operation of frequency-based co-occurrence constraints of all the cues that are available in the input (cf. Elman 1990). As of yet, no completely worked out version of such is model that adequately deals with most of the fundamental observations in sentence processing is around. Nevertheless, on the basis of its general architectural principles the prediction for the neural architecture is that no syntactic processor can be isolated in the brain. We will have more to say about this issue in the next section.

Note that it is not an inherent feature of constraint-based models that no syntactic output is generated. Although constraint-based parsing models often make a connection between the interactive conspiracy of all available cues and the absence of separate semantic and syntactic components, this is by no means a logical or necessary connection. Thus although all constraint-based models agree that all rekevant sources of infornation immediately and jointly contribute to sentence interpretation, in some of these models the joint contribution of the relevant cues results in a syntactic output (e.g. McRae $u$ al. 1998; Tanenhaus et at., in press). Jn short, whether or not sentence-level comprebension requires an intermediate level of the computation of sentence form (syntax) is still a matter of considerable debate.

The issues discussed above have been the subject of experimental research and computational modelling in the psycholingutistics of sentence processing. Until 
now, these issues have not been central to brain-imaging studies on sentence-level processing. Only ERP studies of recent years have started to investigate the central clatins of different parsing models. It is to the electrophysiological evidence on parsing that we will first turn.

\subsection{The microvolts of syntax: electrophysiological evidence}

The discussion of ERP affects related to parsing can only be put in the right perspective against the background of another set of ERP effects that are sensitive to different aspects of sentence processing. Historically speaking, the discovery by Kutas and Hillyard (1980) of an ERP component that seemed especially sensitive to semantic manipulations marks the beginning of an increasing effort to tind and exploit language-relevant ERP components. Kutas and Hillyard observed a negative-going potential with an onset at about $250 \mathrm{~ms}$ and a peak around $400 \mathrm{~ms}$ (hence the $\mathrm{N} 400$ ), whose amplitude was increased when the semantics of the eliciting word (i.e. socks) mismatched with the sernantics of the sentence context, as in He spread his tiam brect with socks. Since 1980, much has been learned about the processing nature of the N400 (for extensive overviews, see Kutas and Van Petten 1994; Osterhout and Holcomb 1995). lt has been found that most word types (e.g. nouns, verbs, etc.) in the languige elicit an $\mathrm{N400}$ (cf. Kutas 1997). As such the $\mathrm{N} 400$ can be seen as a matker of lexical processing. The amplitude of the $\mathrm{N} 400$ is most sensitive to the semantic relutions between individual words, or between words and their sentence and discourse context. The better the semantic fit between a word and its context, the more reduced the amplitude of the N400. This is illustrated in Fig. 9.I, where waveforms are showu for words that vary in a very sabtle way in their degree of semantic fit with the context (Hagoort and Brown 1994). ERPs to sentences of the following types were compared (the critical words are in italics):

(8) a. The girl put the sweet in her mouth after the lesson.

b. The girl patt the sweet tin her porket after the lesson.

Independent behavioural evidence indicates that it is easier to fit semantieally month into this sentence context thim pocket (Hagoort and Brown 1994). As can be seen in Fig. 9.1, the N400 amplitude to mouth is smaller than the N400 amplitude to pocket.

Modulations of the $\mathrm{N} 400$ amplitude are quite generally viewed as directly or indirectly related to the processing costs of integrating the meaning of a word into the overall meaning representation that is built up on the basis of the preveding language input (Brown and Hagoort 1993; Osterhout and Holcomb 1992). This holds equally when the preceding language input consists of a single word, a sentence, or a discourse.

The N400 is usually largest over posterior scalp sites with a slight right hemisphere preponderance in reading but shows no laterality effects with spoken input. Intracranial recordings have suggested an N400 generator in the anturior husiform gyrus (Nobre et al. 1904, but see Kulas ot al., (Moupter 12 this voluthe). 
Jenny put the sweet in

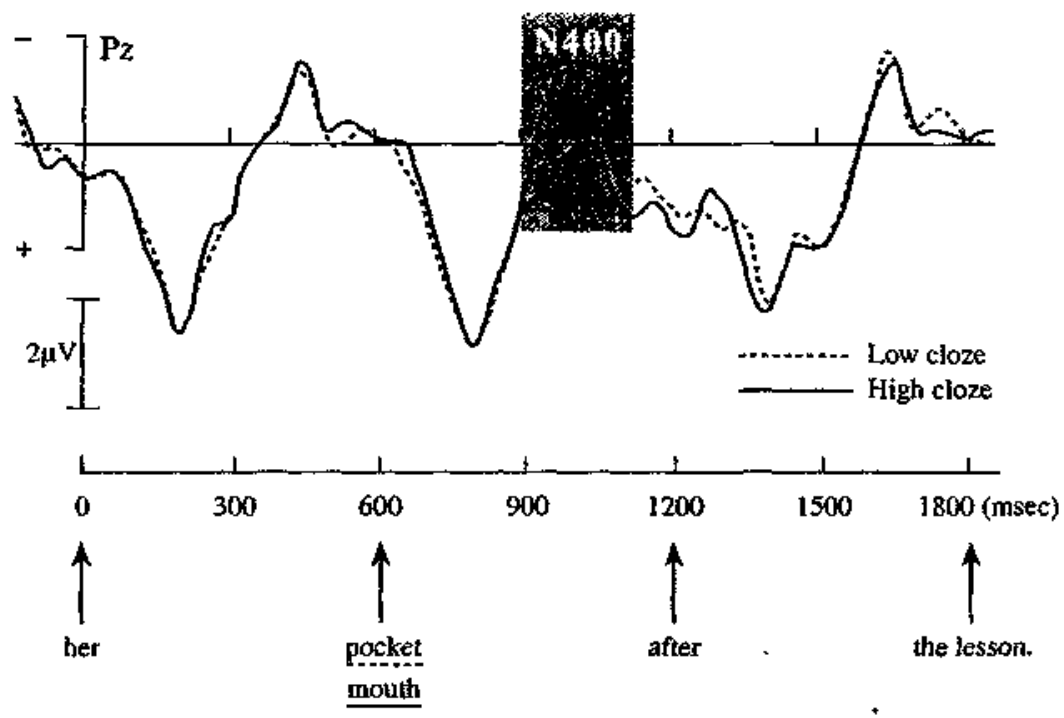

Fig. 9.1 Modulation of the N400-ampdifude as a resull of a manipulation of the semanlic fit between a lexical item and its sentence context. The grand-awerage wavelorm is shown for electrode site $\mathrm{P}_{2}$ (parielad michine), for the bes! fitting word ( $\mathrm{high}$ Cloze; solid line), and a word that is less expected in the given senilence context (Low Cloze; dashed line). The sentences were visually preserted word by word, with an inter val (SOA) of $600 \mathrm{~ms}$. In the ligure the critical words are preceded and followed by one word The crilicat word is presented at 600 ms on the time axis. Negativity is up on the $y$ axis in this and alf other figures. (Adapled from Hagoort and Brown (1994). Copyright (5) 1994 Erbaum, reprinted by permission,

Jackendoff (1997; Chapter 3 this volume) has argued for a tripartite architecture of the language faculty, in which conceptual/semantic structures, phonological structures, and syntactic structures are crucial in language processing. In relation to language, the $\mathrm{N} 400$ amplitude modulutions have been reliably linked to the processing of concepual/semantic information. In recent years, much ERP research has been devoted to establishing ERP effects that can be related to the other two qualitatively distinct types of information that are involved in understanding language.

Relatively little is known about phonological ERP effects. Some studies (Prelamstrs of al. 1994; Rugg 1984a,b; Rugg and Barrett 1987) have reported ERP effects to mamipulations of phonological structure that are reminiscent of $\mathrm{N} 400$ effects in ternis of their polarity and latency. For instance, Praamstra ef $a$ l. (1994) reported a reduction in the amplitude of an N400-like component when a target word shows rhyme overlap with a preceding prime, compared with the ERP waveform to a target word with no phonological overlap with the preceding prime. The isste of whether the stalp 
topography of these effects is identical to the topography of the semantic N400 effects is not yet complefely settled. Other studies have reported phonological ERP effects that are both earlier (Hagourt and Brown, in press) and functionally dissociable from the classic N400 effects (Connolly and Phillips 1994).

In the remainder of this section we will focus on ERP corralates of syntactic processing. Two issues will be centrat to our discussion of syntax-related ERP effects. The first one is what these effects imply for the functional components of syntactic processing. The second issue concerns the inferences that they allow with respect to the neural architecture of the parser.

\subsubsection{ERP evidence for functional components of syntactic processing}

A first distinction should be made between lexical-syntactic effects and syntictic effects beyond the lexical level. Lexical-syntactic effects concern the activation of lemma information that specifies the syntactic features of lexical items. This lemma information is the crucial inpat for the computation of sentence structure.

So far, ERP studies have mitinly tested the distinction between two broad classes of words, namely closed-class (or function) words and open-class (or content) words. The category of closed-ciass words contains, among others, articles, conjunctions, and prepositions. The category of open-class words contains nouns, verbs, and adjectives. Broadly speaking, the distinction between open- and closed-class words can be seen as a basic reflection of the separation between senantics and syntax. The open-chass words are the matin bearers of meaning in the language, providing the bujlding blocks for the overall sense that is contained in a spoken or written santence. In contrast, the closed-class words are rebatively devord of meaning. However, they serve an important role in that they provide crucial information for the computation of the syntactic relations that hold among the open-class words of a sentence.

A series of ERP studies (Brown et $\alpha /$ 1 1999; King and Kutas 1998; Neville ef al. 1992; Nobre and McCarthy 1994; Osterhout et al. 1997a, Pulvermuller et al. 1995) investigated the ERP profiles for open- and closed-class words. Afl studies reported early differences between these two word classes around $280 \mathrm{~ms}$ after word onset. At this latency closed-class words showed an increased negativity that was most prominent over left anterior electrode sites (see Fig. 9.2).

In some studies, this $\mathrm{N} 280$ component was only seen to closed-class words (Neville et al. 1992; Nobre and McCarthy 1994). In these studies the open-class words elicited an $\mathrm{N} 400$ with a posterior distribution. This qualitatively distinct ERP componentry to closed-and open-class words was seen as evidence for separats brain systems subserving the processing of these two word classes. Other studies, however, falied to find this qualitative distinction, and observed the same componentry to open- and closedclass words, with, however, a longer latancy lor lla oppelz-class words (sec lig. 9.2; Brown et $a l$. 1999; King and Kntas 1998; Osteriout et al. 1947a).

Usually word lenghl and word frequency are confounded with the word class distinction, with closed-cluss words being shorter and more freqtuent than open-class words. Some studies have found that these variables account for most of the variance 


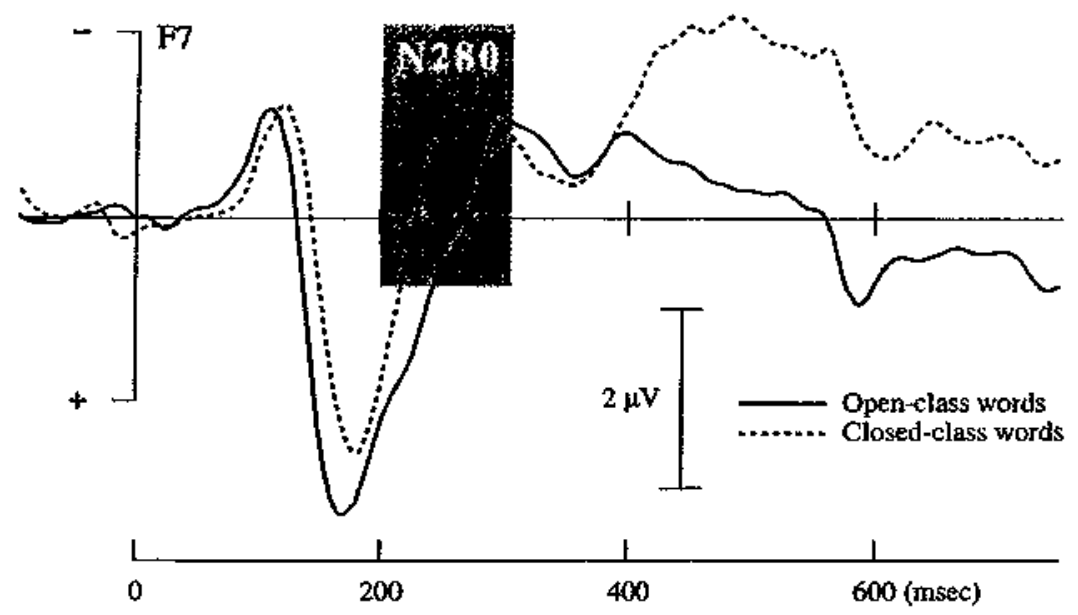

Fig. 9.2 The averaged EFP wavetorms for open- and closed-class words at electrode site F7 tover the left tronlat conlex). The ERP data were collected while subjecls read a simple, lairytale-like story. presented word by word with an interval (SOA) of $800 \mathrm{~ms}$. The open-class wavelorms (solid line) were averaged over nouns (202), acjectives (86), and verbs (151). The closed-class waveforms (dashed line) were averaged over articles (212). prepositions (115), and confuncts (71). Although the waveforms already diverge at around $200 \mathrm{~ms}$ (the P200), this difterence is elther seen as resulting from the upcoming negalivity of the closed-class iterns, of from pretextical processing The closed-class words show a negatwe peak (N280) that is earter than the negative peak for the open-class words. in addition, the closed-class itens sthow an lncreased negative shith in the later part of the waveform, between 400 and 800 ms. (Adapted from Brown, Hagoont, and 1er Keurs 1999)

between the ERPs to open- and closed-class words (King and Kutas 3998: Osterhout et al. 1997a). However, other studies only found an effect of word class, and failed to find a differential effect of length and frequency (Brown et al. 1999; Neville at al. 1992: Nobre et $a$. 1994).

Since the results of current studies differ with respect to the issue of whether the same or different ERP components are elicited by open- and closed-class worts, it is too early to conclude that the processing of these two word types is subserved by the same or different neural tissue. However, independent of this latter issue, the conclusion must be that some of the syntax-relevant word class information is available for further processing in less than $280 \mathrm{~ms}$. Whether this syntax-relevant word-class information emerges from length and frequency parameters, or directly from word-class specifcations, is still unclear. Moreover, whether the time course estimation of word-cluss retrieval gentralizes to other types of lemma information, stud as the grammatical gender of a noun or the syntactic frame of a verb, also remains to be seen.

Once lenmu information has been retrieved during comprehension, syntactic (and possibly other) constraints conspire to structure the linear string of temmas into at hierarchicully organized constituent structure. Two classes of ERP effects bave been 
reported in relation to postlexical structure building operations. The first class of ERP effects are modulations of a negative-going potential with a frontal maximum. The amplitude modulations of this potential are usually referred to as the LAN (Left Anterior Negativity; Friederici et at. 1996; Kluender and Kutas 1993). The second class of ERP effects are modulations of a positive-polarity component which is referred to as the P600/SPS (cf. Coulson et al. 1998; Hagoort et al. 1993; Osterhout and Holcomb 1992; Osterhout et al. 1997b).

In addition to ERP studies on assigning lemmas to constituent structures, a limited number of ERP studies have addressed the processing of so-called filler-gap relations (Garnsey et al. 1989; Kluender and Kutas 1993; McKinnon and Osterhout 1996: Mecklinger et al. 1995). Filler-gap dependencies occur in sentences where constituents have been moved from one location to another. The moved constituent is the filler, its original location is known as the gap (Fodor 1978). Filler-gap dependencies exist in sentences with so-called wh-words such as who and which. For instance, in the sentence The little old lady did not remember which dog she had bitten, the filler dog has been extracted and moved up front from the object position after the verb bitten, leaving a postulated gap after this verb. Dependent upon the exact details of the studies, different types of ERP effects have been observed in relation to establishing filler-gap relations (e.g. Garnsey et al. 1989; Kluender and Kutas 1993). We will not discuss these studies here, but refer to Osterhout and Holcomb (1995) for an overview.

\subsubsection{Left anjerior negativilies}

A number of studies have reported negativities that are different from the $\mathrm{N} 4 \mathrm{C}$, in that they usually show a more frontal maximum (but see Münte $e t a l$. 1997), and are usually larger over the left than the right hemisphere. Moreover, prima facie, the conditions that elicit these frontal negative shifts seem to be more sirongly related to syntactic processing (but see below) than to semantic integration. Usually, LAN effects occur within the same latency range as the $\mathrm{N} 400$, that is between 300 and $500 \mathrm{~ms}$ poststimulus (Friederici et al. 1996; Hagoort and Brown, in press; Kluender and Kutas 1993; Osterhout and Holcomb 1992; Münte et al. 1993; Rösier er al. 1993). But in some cases the latency of a left-frontal negative effect is reported to be much earlier, somewhere between 125 and $180 \mathrm{~ms}$ (Friederici at al. 1993; Neville et al. 1991).

The LAN effects are to be distinguished front the N280 that we discussed ahove with respect to the processing of elosed-versus open-class words. The N280 is an ERP component that is seen in an averaged waveform to words of one or more types. For instance, in the averaged waveform for closed-class words one can easily identify at component with a maximal amplitude at around $280 \mathrm{~ms}$ (see Fig. 9.2). The lef-anterior negativity, however, refers to the amplitude difference between two conditions. It is identified by comparing the averaged waveforms of two conditions. That is, in one condition one sees an increased negativity in comparison with another condition. This negative increase is ustally largest over left frontal sites.

In some studies LAN eftects have been reported to violations of word-category constraints (Friederici et al. 1996, Münte e't al. 1993; Rösler $t$ t al. 1993). That is, if the 
syntactic context requires a lenma of a certain class (e.g. a noun in the context of a preceding article and adjective), but in fact a lemma of a different class is presented (e.g. a verb), early negativities are observed. Friederici and colleagues (e.g. Friederici 1995; Friederici $e t$ al. 1996), have tied the early negativities specifically to the processing of word-category information. This, however, seems unlikely in the light of the fact that similar early negativities are observed with number, case, gender, and tense mismatches (Hagoort and Brown in press; Münte and Heinze 1994; Munte et al. 1993). In these violations the word category is correct but the morphosyntactic features are wrong.

Before discussing the functional interpretations of LAN effects, we have to point to one worrisone methodological aspect of many studies reporting these effects. This is that they are picked up to words in sentence-final position. For various reasons, presenting the critical words in sentence-final position can impact the overall morphology of the ERP waveform and by consequence complicate the comparison with results obtained to words in other than sentence-final positions. It is well known in the reading-time literature that apart from local effects, the sentence-final words are often strong ittractors of global processing factors related to sentence wrap-up, decision, and response requirements (e.g. Mitchell and Green 1978; Sehriefers et at. 1995). For example in sentences that subjects judge as unacceptable, final words seem to elicit an enhanced N400-like effect, regardless of whether the unacceptability is semantic or syntactic in nature (Hagoort et al. 1993; Osterhout and.Holcomb 1992, 1993). Osterhout (1997) found that syntactic anomalies were more likely to elicit a noticeable anterior negativity when placed at the end of the sentence than when embedded within the sentence. The ERP effects of the local violation and the more global ERP effects of sentence processing thers tend to overlap most strongly in sentence-final position, thereby affecting the resulting ERP waveforms for the local effect particularty in this position. Cross-study comparisons would thts be made easier if words that realize the critical experimental manipulation were not in sentence-final position.

The functional interpretation of LAN effects is not yet agreed upon, partly for the methodological reasons given above, partly because its antecedent conditions are not yet sufficiently clarified. As indicated above, one possibility is that this effect is specificatly syntactic in nature. Along these lines, it has been proposed that LAN effects are functionally related to matching word-class information against the requirements of the constituent structure derived from the earlier lemmas in the sentence (Friederici 1995). The word-class information might have some temporal precedence over other lexical information in generating a syntactic structure for the incoming string of words (Fricderici et al. 1996). However, as we argued above, this would explain only a subset of the reported LAN effects.

L.AN effects have also been related to verbal working memory (Kluender and Kutas 1993; Coulson et $a l$. 1998). Such an account is compatible with the finding that hoth lexical and referential anbiguties seem to elicit very similar frontal negativities (Hagoort and Brown 1994: Van Berkum et $d$. 1997; see also King and Kutts 1995). These cases refer to the protessing of words with more than one meaning (e.g. hank) aut to the processing of nouns that have more than one antecedent in the preceding 
discourse. Such ambigaties are clearly not syntactic in nature, but can be argned to tax verbal working memory more beavily than sentences in which lexicat and referential ambiguities are absent. This account denies a special relation of LAN effects to syntactic processing, but relutes them to the general resource requirements for langutige comprehension.

It is, however, also miliktly that all frontat negativities that are reported call be subsumed under a verbal working-memory account. For instance, the frontal negattivities elicited by morphosyntactic violations (Mñnte at al. 1993) are dificuft to account for in terms of working memory.

A third possibility is that under the heuding of LAN effects more than one type of effect has been subsumed, which we have not yet been able to separate due to similarity in distribution and latency and a limited understanding of the antecedent conditions. The few reports of very early LAN effects have recently led to the claim that this effect might be at least functionally different from the 'standard' LAN effects in the 300$500 \mathrm{~ms}$ latency range (Friederici 1995; Friederici ef al. 1996). The early effects are now sometimes referred to as ELAN (Friederici et al. 1998). Since research on LAN/ELAN effects has started only very recently, we can expect that some of these issues will be clarified in coming years.

\subsubsection{P600/SPS}

A relatively more stable finding than the reported LAN effect in terms of reproducibility and establishing the antecedent conditions are the later positivities, nowadays referred to as P600/SPS (Coulson et al. 1998; Osterhout et al. 1997b).

One of the antecedent conditions of P600/SPS effects is a violation of a syntactic constraint. If, for inshance, the syntactic requirement of number agreement between the grammatical subject of a sentence and its finite verb is violated (see (9), with the critical verb form in jtalics), a positive-polarity shift is elicited to the word that renders the sentence ungranmmatical (Hagoort et al. 1993). This positive shift starts at about $500 \mathrm{~ms}$ after the onset of the violation and usuatly lasts for at least $500 \mathrm{~ms}$. Given the polatily and the latency of its maximal amplitude this effect was originally refered to as the P600 (Osterhout and Holcomb 1992) or. on the basis of its functional characteristics, as the Syntucic Positive Shitt (SPS) (Hagoort ef al. 1993).

*The spoilt child are throwing the toy on the ground.

An argument for the independence of this effect from possibly confounding semantic fuctors is that it also occurs in sentences where the usual semantic/pragmatic constraints have been removed (Hagoort and Brown 1994). This restits in sentences like (10a) and (10b) where one is semantically odd but grammaticatily correct, whereas the other contisins the same agreement violation as in (9):

(10) a. The boiled watering-can smokics the telephone in the cat.

b. "The boiled watering-tan smoke the telephone in the cull. 


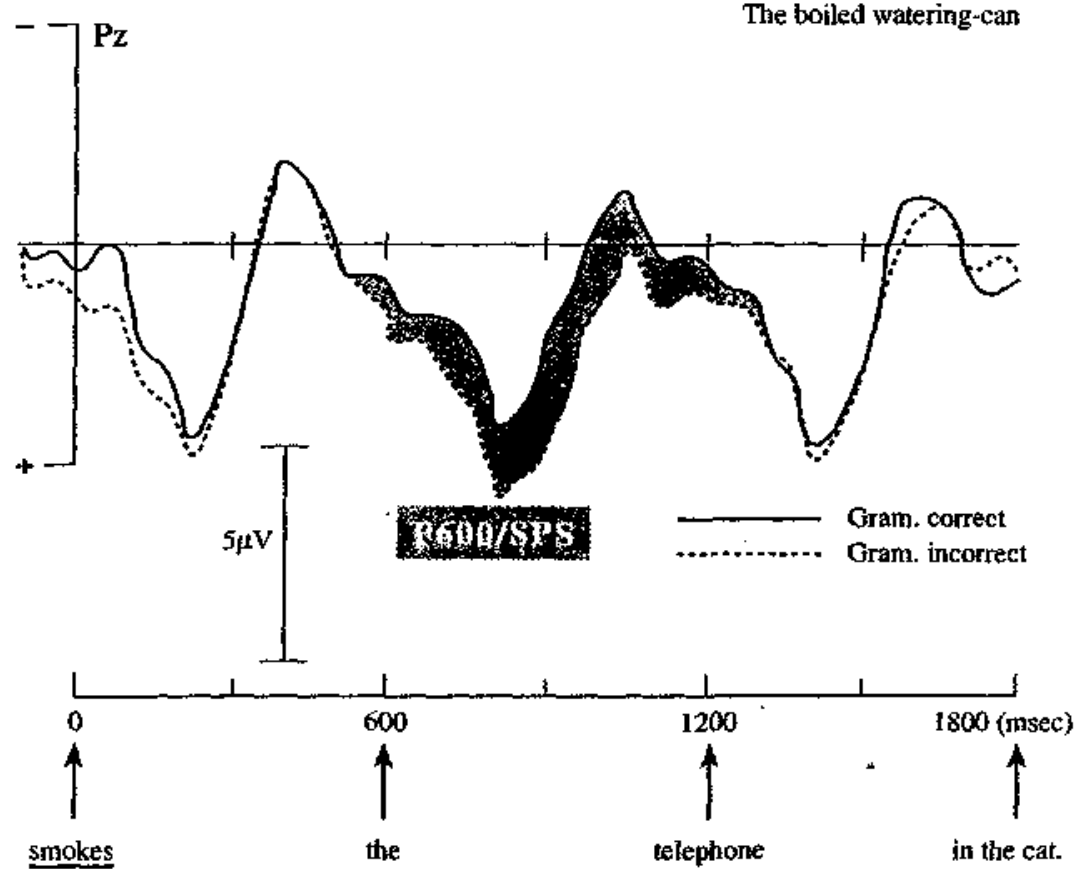

* snoke

Fin. 9.3 EPP. to visually presented syntactic prose sentences. A P600/SPS is eliciled by a violation of the required number agreement between the subject-noun phrase and the firite verb of the sentence. The averaged wavelorms for the grammatically correcl (solid bne) and the grammatically incorrect (dashed line) words are shown for electrode site $\mathrm{Pz}$ (parielal midline). The word that renders the sentence ungrammatical is presented at $0 \mathrm{~ms}$ on the the axis. The waveforms show the EFPs to this and the lollowing two wonds. Hords were presented word by word wh an spterval (SOA) of $600 \mathrm{~ms}$. (Adapted irom Hagoort and Brown (1994). Copyrighl (0) 1994 Erlbaum, reprinied by pernission.)

If one compares the ERPs to the italicized verbs in (10a) and (10b), a P600/SPS effect is visible to the ungrammatical verb form (see Fig. 9.3). Despite the fact that these sentences do not convey any coherent meaning, the ERP effect of the violation demonstrates that the language system is nevertheless able to parse the sentence into its constituent parts. ${ }^{1}$

Similar P600/SPS effects have been reported for a broad range of syatactic violations in different languages (English, Dutch, German), including phrase-structure violations (Hagoort et al. 1993; Neville ot $a$. 1991; Osterhout and Holcomb 1992). sultategorization violations (Ainsworth-Darnell ot al. 1998; Osterhout and Holcomb 1992; Osterhoit et al. 1994), violitions in the agreenent of number, gender. and cuse 
(Coulson et al. 1998; Hagoort et al. 1993; Mũnte at al. 1997; Osterhout 1997; Osterhout and Mobley 1995), violations of subjacency (McKinnon and Osterhont 1996; Neville et al. 1991), and of the empty-category principle (McKinnon and Osterhout 1996). Moreover, they have been found with both written and spoken input (Friederici et al. 1993; Hagoort and Brown, in press; Osterhont and Holcomb [993). ${ }^{2}$

Already in the first P600/SPS studies (Hagoort et al. 1993; Osterhout and Holcomb 1992) it became clear that syntactic violations are not the only antecedent condition of this ERP effect. The other way to elicit this effect is closer to normal sentence processing, since it occurs in sentences that are grammatically correct. It relates to the issue of structural indeterminacy. In on-line sentence comprehension, as one goes along structuring words as they come in, at many points in a sentence the words can be grouped into constituents in more than one way (see example (5)). At these points of indeterminacy, there will nevertheless be a temporary preference (or increased level of activation) for one structure over its alternative(s). Later incoming words can either support the preferred structure, or provide evidence that an alteriative option has to be assigned. This latter case involves extra processing costs. Dependent on the particulars of the proposed parsing model the extra processing costs are ascribed to rejection of the initial structure and the necessary reassignment operattions (Frazier 1987), of to inbibition of the higher attivated structure and increase in activation for the initially less-activated structure (Tanenhaus and Trueswell 1995). It turns out that the word in the sentence that signals this change in preference/ activation also elicits a positive shift reminiscent in latency and polarity of the P600/ SPS. An example can be seen in a recent study by Hagoort et al. (forthcoming), in which the following sentence pairs were compared (the original sentences were in Dutch):

(11) a. The sheriff saw the indian and the cowboy noticed the horses in the bushes.

b. The sheriff saw the indian, and the cowboy noticed the horses in the bushes.

The comma after the noun indian in sentence ( 1 lb) mitks the end of the first clause and signals that after the connective $\mathrm{cmd}$ a sew clause follows. This is different from sentence (11a). Once the indian and the conbry bas been read, the sentence can continue as it does, bat it could also have continued in a structurally different way. The alternative structure takes the string the indian and the cowboy together as one complex noun phrase in the role of the direct object of the verb see. Sentence (12) is an example of this alternative structure:

(12) The sheriff saw the indian and the cowboy after funch time.

In other words, up until reitding sourber the sentence is syntatically ambignous, in that the final structure among tire alteruative options cannot yet be determined. In the absence of infornation that unambigtously determines the strueture (i.e. the verb following the noun couthy one alternative is preferred or more highly activaled. This preference is presunably determined by either syntactic sinplicity (zo for the simplest structure; Frazier 1987) or the frecuency of the different possible syntactic structures 


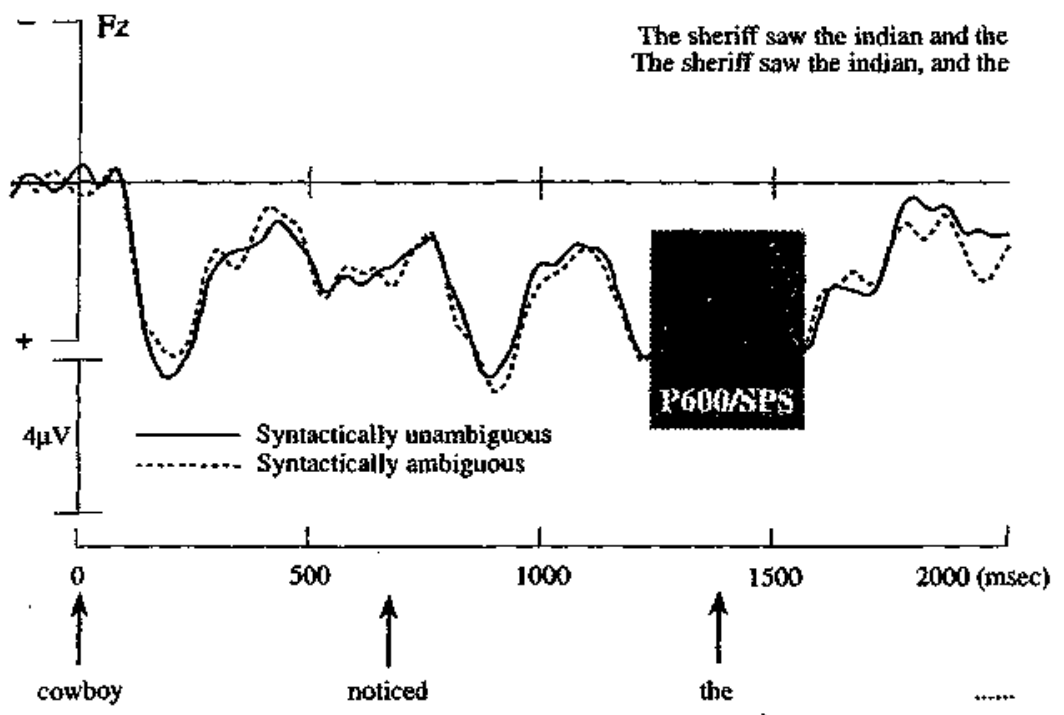

Fld. 9,4 Averaged EFP waveform over the frortal mtdline electrode slie (Fz) tor syntactically ambiguous and unambiguous semtences. Bentences were presented visualy, word by word with an interval (SOA) of $686 \mathrm{~ms}$. In the ambigucus conditron (dashed Ifie), the sentences were inftlally symtactically ambuguous (see text). At the point of disambiguation (at $686 \mathrm{~ms}$ in the itgure) the sentence continued with a grammatically cotrect but non-preferred reading. In the unambiguous control condition (solid tine), the same sentence was presented with the addition of a comma, dictating that only the non-preterred reading was possible. th the Haure the disambiguating word is preceded and followed by one word

(go for the most frequent structure; Mitchell 1994; Mitchell at al. 1995). In both cases the conjoined-NP structure is preferred over the sentence-conjunction. If this preference exists, one should find a processing cost at the following verb which indicates that a conjoined-NP analysis ean no longer be maintained and that the sentenceconjunction analysis is the right one instead. Figure 9.4 shows that indeed a P600/SPS is obtained to the verb noticed in the syntactically ambiguous sentence (11 it) compared to its unambiguous counterpart (1lb). Similar P600/SPS effects of syntactic ambiguity have been reported for English (Osterhout et at. 1994) and German (Friederici et al. 1996).

The presence of $\mathrm{P} 600 / \mathrm{SPS}$ effects to subtic but pervasive phenomena like structurat indeterminacy and structural preference hus been used to address some of the central issues in the parsing literature. One such issue is whether non-syntactic sources of information immediately contribute to structure-building operations. One of these sources of information is lexical in nuttre (Trueswell et al. 1993). Another possibly relevant source is the discourse context in which sentences are normally embedded (Aitmann 1988: Altmmn and Steedman 1988; Crain and Steedman 1985; Niet $t$. 1996). 
Whether lexical information guides parsing was investigated in another condition of the Hagoort ef at. (fortheoming) study. The same struetural ambiguities were tested as in ( $1 \mathrm{a}, \mathrm{b}$ ). This time, however, the semantics of the main verb preceding the two nouns connected by and went together with an animate but not with an inanimate object. Nevertheless, if the structural analysis is initially only determined by syntactic cues, the lexical-sematatic verb bias should not help. So, the structural preference for a conjoined-NP analysis over a sentence conjunction analysis should also hold in (13a), resulting in a P600/SPS to the main verb of the second clause (vanisfes). If, in contrast, lexical-semantic information is used immediately during structural analysis when reading the second noun of the coordinate structure, it is immediately clear that this noun (skipper) cannot be inserted into a conjoined-NP analysis and thus hats to be the subject of a second clause. This predicts that the ERPs for the main verb of the second clause (in italics) are identicul in (13a) and (13b).

(13) a. The helmsman repairs the mainsail and the skipper vamishes the mast of the battered boat.

b. The helmsman repairs the mainsail, and the skipper varnishes the mast of the battered boat.

The ERP results showed no difference between sentences of type (13a) and (13b), indicating that semintic constraints are used immediately and in parallel with syntuctic constraints during the assignment of a constituent structure to an incoming string of words.

In another experiment that addressed the influence of lexical information on parsing. Osterhout et al. (1994) had subjects read sentences of the following type (the critical word for the ERP comparisons is in italics):

(14) at. The doctor hoped the patient was lying. (pure intransitive verb)

b. * The doctor forced the patient was lying. (pure transitive verb)

c. The doctor believed the patient w'as lying. (intransitively biased verb)

d. The doctor charged the patient was lying. (transitively biased verb)

These sentences can be distinguished in terms of the lenma information associated with the main verb in euch sentence. In this case the specific lemma information concerns the subcategorization properties of the verbs. For sentences (14a) and (14b) these properties fully determine the role of the following noun plarase ( $t / k$ patient). Specifically, the intransitive verb hope in (14a) does not allow a direct object-noun phrase, unambiguously indicating that the noun phrase is the subject of an upcoming clatuse. The lemme information ol' the transitive verb fore in (14b) specifies that it requires a direct object, implying that in this case the same noun phrase must be 
assigned the direct object role. Sentence (14b) becomes ungrammatical at the auxiliary verb, since the sentence-final phrase ras lying prohibits the necessirry direct object role for the preceding noun phrase.

The verbs in (14c) and (14d) can be used both with and without a ditect object. This introduces temporary syntactic ambiguity upon encountering the following noun phrase. since the patient might be acting as the direct object of the verb, or as the sabject of a forthcoming clause. However, although both believ and charge can be used transitively and intransitively, one is more often used istransitively (belicl $\left({ }^{\prime}\right)$, the other more often transitively (charge). This induces different lexically specified subcategorization preferences for these two verbs.

The question is whether these lexical preferences rapidly influence the assignment of structure to the sentence. According to so-called depth-first serial parsing models (Frazier 1987; Frazier and Rayner 1982), in the first instance the simplest structure is always assigned in case of ambiguity. Since the direct object analysis is syntactically simpler than the subject-of-a-clause analysis, there should be an initial preference for the first structure independent of the lexically specified preferences associated with the particular verbs. Alternatively, constraint-based parsing models predict that these lexically-specified preferences immediately influence the syntactic analysis (Truesweli et al. 1993). Given the different verbal preferences, this model predicts that the subject role will be correctly assigned to the noun phrase in (14c) since the verb belike 'prefers' to be used without a direct object. Jn (14d) injtially the same noun plorase will be erroneously assigned the direct object role, since the verb charge "prefers" to be used transitively, that is with a direct object. This should show up as a parsing problem at the auxiliary verb in sentences like (14d).

In summary, a depth-first parser predicts syntactic anomaly/preference effects at the auxiliary verb in sentences like (14b), (14c), and (14d). A constraint-based parser predicts such effects only in sentences like (14b) and (14d).

Osterhout et al. (1994) presented these types of sentences (for details see Osterhout et at. 1994), and compared the ERP waveforms to the auxiliary verb (Iras) in each sentence type. Figure 9.5 summarizes the results. As expected, the syntactic violation in (14b) elicited a large P600/SPS, that was maximal over purietal sites. More importantly, auxiliary verbs that followed transitively biased verbs (14d) adso elicited a $\mathrm{P}(\mathrm{f}) \mathrm{O}_{\text {; }}$ SPS, although with a sinaller amplitude than for the outright violation. ERPs for auxiliary verbs in sentences with an obligatorily intransitive verb (14a) and sentences containing a verb with an intransitive bias ( $14 \mathrm{c}$ ) did not differ from etch other and dicl not elieit a P600/SPS.

As in the Hagoort et $a l$ study (forthconing), these data show that texical preferences can immediately guide the structural analysis of a sentence. Recently. P600/SPS effects have been observed in a study investigating whether discourse information had an immediate effect on the struetural analysis of a following senterce (Van Berkum et ul. 1999). The pattern of effects indicated that discourse information also immealiately co-determines the structural analysis. at least in cases where more than one structure (i.e. it relative ctause vs, a complement clause) coukl be kegally assigned. 


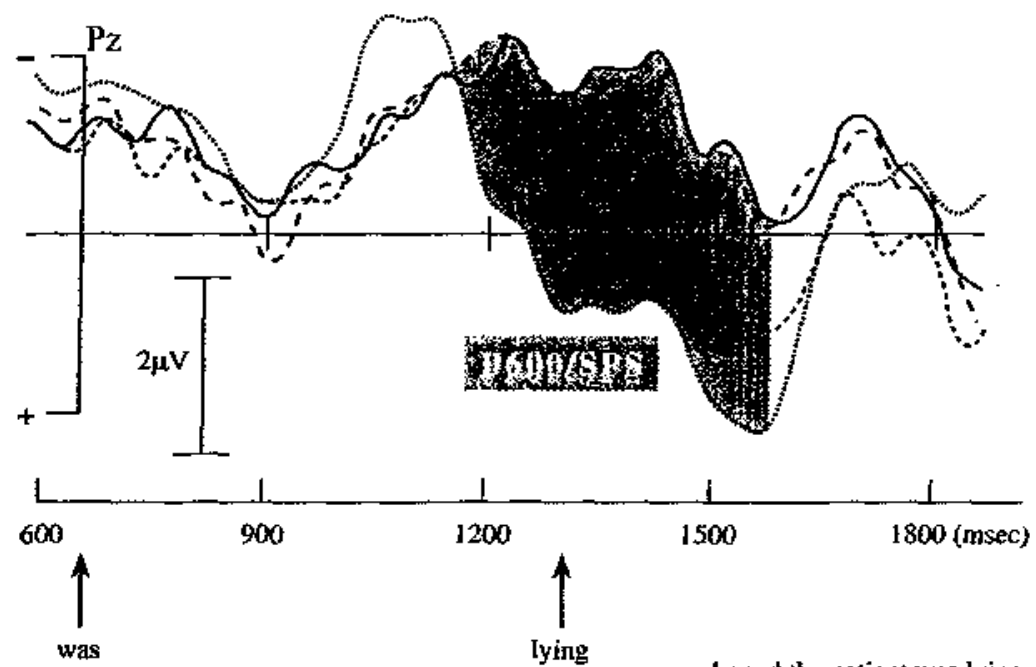

- hoped the patient was lying.

- - - believed the patient was Jying. * forced the patient was lying. charged the patient was lying.

Fig, 9.5 Averaged EFP waveforms from $P z$ tparielal midine) to the thal three words in each of lour sentence types (see lext) intransntve (solid fine), transitive (dotted bine), intransitively based (medhum-dash sine), and transtively biased (smat-dast line). The crilical auxilary verb starts at $0 \mathrm{~ms}$ on the time axis as marked by the arrow. Sentences were presented visually and word by word, with an interval (SOA) of $650 \mathrm{~ms}$, (Addapted from Osterhoul et al. (1994). Copyright 1994 Arnerican Psymhological Assoclation, reprinted by permission.)

Importantly, the influence of non-syntactic cues might be restricted to a sitzation of syntactic indeterninacy, sucls as when the input allows more than one syntactic analysis. If no alternative analysis is possible, the P600/SPS to a syntactic violation is found not to be affected by an additional semantic violation (Hagoort and Brown 1997). This suggests that when the syntactic analysis is fully determined by the lemma input, syntactic processing is relatively independent of non-syntactic cues,

\subsubsection{Topographical aspects of the P600/SPS}

An important, but often complex aspect of ERP duta is the siniliarity or dissimilarity across experiments in the topographical distribution of the scalp-recorded polentiats (cf. Kutas 1997). Especiatly for the longer latency components related to higher cognitive functions, it is most likely that a distributed ensemble of neuxal generators is contributing to the recorded surface potentials. That is, a particular langange-relevant ERP effect (e.g. an N400 or a P600/SPS effect) is almost certainly based on the concerted action of a number of brain areas. Some of these areas sutrerve the core aspects of a cognitive function, others might be related to the input cinamel fauditory, 
visual) that triggers a cognitive function (e.g. parsing). This often complicates the functional interpretation of topographical differences. Answering the question when a topographical difference is central (i.e. different processing components involved) or peripheral (e.g. resulting from the attentional modulation of core processes) with respect to the core aspects of a cognitive function is far from trivial. This also holds for the P600/SPS effects.

Atthough syntactic violations and syntactic preferences both elicit a positive shift within about the same latency range, there are nevertheless clear topographical differences between these two cases, and sometimes even between different types of ambigasity. Generally speaking, the P600/SPS to syntactic violations shows a posterior maximum, whereas the syntactic preference effects are more equally or more frontally distributed. Furthermore, it has been reported that for syntactic violations the initial phase ( $500-750 \mathrm{~ms}$ ) of the P600/SPS has a fatily equal scalp distribution, whereas the second phise ( $750-1000 \mathrm{~ms}$ ) shows a clear parietal maximum (Hagoort and Brown, in press). It thus could be that the P600/SPS is not one effect but a family of effects, with the (additional) contribution of different generators in the early and late phase of the effect, related to functionally different states of the parser. A tentative hypothesis is that the processing costs associated with overwriting the preferred or most activated structure results in a more frontally distributed P600/SPS, whereas a structural collapse as in outright syntactic violations results in a more posterior P600/SPS.

Recently, a few studies have claimed that the P600/SPS belongs to the family of classical P300 effects (Coulson et al. 1998; Gunter et al. 1997; Mante at al. 1998). This claim is based on the finding that the amplitude of the P600/SPS is sensitive to the probibility of a syntactic violation. The less probable such a violation, the larger the anplitude of the P600/SPS. However, the crucial aspect for answering the question of whether the P600/SPS is a member of the P300 family is not whether probability has an effect on the anplitude of the positive shift. It is unlikely that only one brain response is sensitive to probability, and hence it does not follow that just because the P300 is probability-sensitive, any ERP effect that shows a similar sensitivity to probability is therefore a P300. Secondly, since the ERP waveform is often a composite of more than one underlying process, the increase of the positive shift to a syntactic violation as a function of the probability of such a violation does not necessarily imply that the probability effect can be ascribed to the same underlying newral generators as the syntactic violation effect. This, for instance, would be difficult to argue for if the effects of violation and probability were additive. According to Helmholz' superposition rule, if the scistp-recorded ERP effects of syntactic violations and of probability differences are additive, ore is entitfed to assthme that the generators of the violation effect ind the generators of the probability effect are non-overlapping. Osterhout et al. (1996) showed that the syntactic violation effect and the probability effect are additive, indicating that the generators of the syntactic violation effect are most likely not the standard $P 300$ generators. Finally, as we have disetussed above, in interesting cases of syntactic processing the distribution of the P600/SPS is very different from the posteriorly distribtited elassical P3b component. So far convincing evidence for the ctaim 
that the P600/SPS is generated by the classicat P300 generators is lacking (for a more extensive discussion, see Osterhout and Hagoort 1999).

However, more importantly, unless one wants to make clains atbout the languagespecificity of the P600/SPS (at claim that, at present, cannot be made for any of the language-relevant ERP components), not much hinges on the outcome of the P(60)/ SPS versus P300 debate. As holds for the other kangiage-relevant ERP effecis, how directly or indirectly they are related to the actuil processors that operate on the inpul is unknown (Rugg and Coles 1995). But this does not limit the vatue of ERPs for the study of the neurocognitive machinery underlying language functions. As long as under conditions of linguistic input different ERP effects can be shown to supervene on the processing of different types of jinguistic information (e.g-phonological, syntactic. conceptual/semantic), these effects can be exploited to study the segregution and interaction of the different knowledge types, and to make inferences about the similarity versus dissimilarity of the concomitant brain states.

\subsubsection{The implications of ERP eftects for the neural architecture of parsing}

Inferences about the neural basis of cognitive processing from scalp-recorded surface potentials are complicated by a number of issues (for an in-depth discussion, see Kutas "' $a l$., Chapter 12 this volume; Rugg, Chapter 2 this volume; Rugg and Coles 1995). A first complication is the impossibility to uniquely determine the location of the neural generators responsible for the surface potentials on the basis of only the information of the surface recordings. This so-called inverse problem severely restricts the localization value of ERPs in the absence of independent neurophysiological constraints on the brain areas that might be involved in generating the fanguagerelevant ERP effects.

A second complication is that we do not know whether the cognitive processes that we are interested in are directly or only indirectly reflected in the ERP effects. This complication has its parallel in PET and FMRI whore it is often unknown whether an area with an increased hatemodynamic response is the source of the cognitive opcration or the site where it has its effect. With respect to ERPs, with their millisecond timecourse resolution, we face the problem that if the scalp-recorded potential is only indirectly related to the cognitive operation under investigation, the time course of the ERP is displiced in time relative to the time course of the cognitive operation by itn unknown amount. This implies that the latency of an ERP eflect reflects the upper bound on the estimation of the time courst of a cognitive operation (Rugg and Coles 1995). The time of the cognitive operation might have preceded the moment where it started to manifest itseif in its ERP inctex.

Related to this second complication is that it is unclear and unlikely that the fanguage-relevant ERP eftects that we discussed are also language-specilic. That is, presumably other domains of cognitive processing also drive all or at sabset of the neural generators that elicit the language-relevant scalp-tecorded potentials. For instance, structural violations in music also seem to elicit P600/SPS effects (Patel e' al. 1998), and sementic violations in the form of pictures elicit N400 effects that are not 
unlike the N400 effects with linguistic input (Ganis et al. 1996). However, again this does not limit the usefulness of ERPs, provided that the right experimentat controts are carried out. What is important is that under conditions of language input the beluviour of the different ERPs can be causally linked to the different constituting elements of the neurocognitive machinery for language.

With these provisos in mind, can we nevertheless claim anything of interest about the neural basis of syntactic computations? The answer is yes, under the reasonable assimption that the generators of the language-relevant scalp-recorded potentials supervene on the spatiotemporal aspects of the neural machinery that subserves language processing. This implies that if two states of the neural machinery for langlage are identical, they cannot give rise to ERP effects that are qualitatively distinct (i.e. different in polarity or topography), provided that the experimental design controls for the contribution of non-language variables such as, for instance, attention. Finding qualitatively distinct ERP effects can thus be seen as an indication of the processing and/or representational uniqueness of the underlying component of the neurocognitive machinery.

The observation that qualitatively distinct ERP effects are elicited (directly or indirectly) by semantic integration processes and syntactic structure building operations thus suggests that these aspects of language processing have a non-identical spitiotemporal neural profile. This difference favours a view in which semantic and syntactic processes bave processing and/or representational uniqueness relative to each other. The neural basis of syntactic computations can therefore not be collapsed into a general-purpose language processor that operates only on the co-occurrence frequencies of the word input, or in which semantic and syntactic factors do not result in clearly different states in the processing/representational landscape (cf. Tabor and Tanenhaus 1998). The claim for the uniqueness of semantic and syntactic processes and/or representations is further supported by the finding that in severely agrammatic aphasies a dissociation between P(60/SPS and N400 effects can be obtained. That is, under certain syntactic violation conditions, the P600/SPS disappears but the N.t(F) effects remain (Wassenaar ef $a l$. 1997).

In conclusion, although the inverse problem prevents sfrong claims about the location of the generator ensembles of language-relevant ERP componentry, nevertheless the nature and the differeatial sensitivity of this componentry places constraints on the neural organization of langunge functions. On the basis of the ERP datu one can best charatetize this organization as a dynamic coalition of multiple areas of relutive specialization. The boundary conditions of the current ERP evidence thtis fovour independent but partially interactive semantic and syntactic processors. In contrast to single-processor models of sentence processing, the ERP evidence predicts that networks for syntactic and semantic processing are at least partially segregated in the brain.

With respect to the functional organization of sentence processing, the ERP evidence suggests that the syntactic processor (parser) is influenced by lexical-semintic ant pragtatisic information most ckatrly when the lemma input and the syntactic 
constraints leave roon for structural indeterminacy. If, however, the syntactic information allows only one structure to be assigned, semantic influences on parsing are limited or absent (Hagoort and Brown 1997; for supportive evidence from reactiontime research, see O'Seaghdha 1997).

\subsection{Brain areas and syntax: evidence from lesions and PET/fMRI}

Although ERP evidence provides some insights in the fractionation of the neural machinery for language, for more precise assignments of syntactic functions to bratin structure we have to turn to other methods. Evidence on the brain areas involved in syntactic processing comes from two sources. These are lesion studies and brainimaging studies. Ideally these two sources of evidence should atlow us to determine the areas that are necessiry (lesion data) and sufficient (brain-imaging data) for gratumatical encoding operations during speaking and parsing operatjons during language comprehension. However, as we shall see, the picture that energes from this literature is not yet clear. A number of different factors might be responsibie for the inconsistencies in the results of lesion and brain-imaging studies. Among these faclors are (i) the use of designs that insufficiently single out syntactic operations from other sentence-level processes, or from task-related cognitive operations; (ii) the failure to distinguish between grammatical encoding (cf. Levelt, Chapter 4 this volume) and syntactic parsing (cif. Cutler and Clifton, Chapter 5 this volume; Perfetti, Chapler 6 this volume), which might operate under quite distinct processing reguirements: (iii) interindividual variability (both anatomical and functional) which might be substantialiy larger for absiract linguistic operations than for sensory and motor functions (Bavelier et al. 1997; Caplan 1987).

In this section we will first summarize the results from lesion studies, followed by an overview of the carrent PET/AMRI data. We will then come bick to the claims that can be made on the basis of the available evidence.

\subsubsection{Lesion studies}

The slissical Wernicke-Lichthein netal model of litnguitge and its revivit by Geschwind (1965) focused completely on the processing of words. It was bot until the beginning of the seventies that the sentence came back on stage as a tentrat unit of analysis (for the historical roots of a reorientation from word atphasiology to sentence aphasiology in the beginning of this century, see De Bleser 1987). It is in this period that left-anterior brain damage, in particular Broca's area, becume associated witl syntactic impairments in all language modalities. Broca's aren is usualiy taken to encompass Brodmann areas 44 and 45 (see Uylings st al. Chapter of this volume). Although classically Broca's aphusia was seen as mainly affecting speech outpu. stadies carried out in the seventies have shown that Broca's apisasics are not onfy impaired in syntactic encoding, but also in exploiting syntactic information during sentence interpretation (Caramazza and Zurif 1976; Heilman and Scholes 1976; Von Stockert and Bader 1976: Zurif et al. 1972). On the basis of these studies. Brocil 's areal 
came to be seen as crucially involved in both grammatical encoding and parsing operations. Modality-independent grammatical knowledge was thought to be represented in this area (Zurif 1998). However, since then the pivotal role of Broci's area in syntactic processing has faced a number of serious problems. Studies that correlated aphasic syndromes with site of fesion led to the conclusion that the relation between Broca's area and Broca's aphasia is not as straightforward as once believed, for a number of reasons.

First, lesions restricted to Broca's area often do not seem to result in lasting aphistc (including agrammatic) symptoms (Mohr et al. 1978). According to Mohr et al, involvement of adjacent frontal-opercular areas, the parietal operculum, and the insula are also required for a long-lasting Brocit syndrome.

Secondly, large-scale correlational stuởies found a substantial number of exceptions to the general rule that left frontal tesions go together with Brocu's aphasia (Basso et al. 1985; Wílmes and Poeck 1993). Basso at al. (1985) correlated cortical lesions as revealed by CT scans with aphasiological symptomatology for a group of 207 patients. They reported a substantial number of exceptions ( 17 per cent) to the classical associations between lesion site and aphasia syndromes. Among these exceptions were patients with lesions restricted to left-anterior areas, but witl a fluent aphasia of the Wernicke type (seven cases), as well as non-fluent Broca's aphasjos with posterior lesions atnd sparing of Broca's area (six cases). Willmes and Poeck (1993) investigated the CT lesion localization for a group of 22I aphasic patients with a vascular lesion in the territory of the middle cerebral artery. Their results were even mote dramatic. The conditional probability of an anterior lesion given a Broca's aphasia was not higher than 59 per cent, whereas the probability that an anterior lesion resulted in a Broca"s aphasia was only 35 per cent.

Thirdly, impuirments in syntactic processing have also been reported in Wernicke's aphasics with posterior lesions (e.g. Heeschen 1985), indicating that other areas might be crucial for syntax as well.

Fourthly, cases hive been reported of patients in which an impairment in grammatical encoding was observed without a concomitant impairment in parsing (Kolk (' al. 1985; Miceli at al. 1983; Nespoulous et al. 1992). These findings saggest that bratin areas involved in grammatival encoding night not necessarily be the sitme as the ones involved in parsing.

In addition, more recent studies indicate that the syntactic deficit in Broca's aphasics is probably more limited than was believed in the seventies. Many agrammatic patients with Broca's aphasia show a relatively high sensitivity to syntactic structure in tasks such as judging the grammaticality of sentences (Linebarger et al. 1983). With respect to their language output, recent analyses indicate that the telegraphic style of agram. matic aphatsics lollows the syntactic regalarities of elliptit utterances, and therelore shows syutactic competence at lesst to some degree (Kolk and Heeschen 1992).

In summary, the view that a central syntactic deficit is the distinguishing feiture of Brocu's aphasia and that Broca's area therefore is a cricial area for grammatical encoding and parsing is difficult to nuintain in the light of more recent 
netrolinguistic studies and lesion stucties correlating Broca's aphasia with the concomitant lesion sites.

However, there are good retsons to consider all this evidence as not really decisive with respect to the role of Broca's areat in syntactic processing. Ome major reason is that the characterization of the language disorder in lesion studies usually is based on clinical inpressions (Mohr et $a$. 1978) or clinical aphasia tast batteries (Basso et al. 1985; Wilmes and Poeck J993), which are often insufficient to determine the degree and specifieity of the syntactic inmairment. The classification of aphasic patients in terms of a limited set of syndromes is insufficient guarantee that core language operations are singled out according to articulated cognitive architectures for speaking, listening, or reading (cf. Shallice 1988). Willmes and Poeck (1993, pp. 1538-39) therefore rightly conclude that

... Jocalization stadies ulong the traditional lines will not yield reșuls that leond themselves to a meaningful interpretation of impaired psyclrological processes such us aphasia. Small-scalc in-depth studies lend themselves better to characterizing the functional impairment in an information-processing model.

In recent years a small number of such in-depth studjes have appeared (Caplan it $\mathrm{al}$. 1985, 1996; Dronkers ef al. 1998; Vanier and Caplan 1990). In these studies, aphasic patients were selected on the basis of specific tests of their syntactic abilities. In both Caplan et $a l .(1985)$ and $C$ aplan $e t a l$ (1996) patients were tested on a series of sentence types that required them to process a range of syntactic structures. These studies showed that the task performance for the different sentence types did not differ between patients with anterior (Broca's area) and patients with posterior lestons. The size of the lesion within the perisylvian area also did not correlate with the syntactic task performance. The lesion analysis of 20 agrammatic aphasics in Vanier and Caplan (1990) suggests that this conclusion not only holds for sentence comprehension but also for sentence production. Caplan et al. (1996) give two possible explanations for these results. One possibility is thit syntactic processing is fairly strictly localized, but the exact site wn vary quite substantially between individials within the borders of the left perisylvian area including the insula (Caplan 1987; Vanier and Caplan 1990). The other possibitity is that the syntactic machinery is organized as a distributed neural network in which several regions of the left perisylvian cortex are critically involved.

In contrast to the lesion studies by Citplan and colleagues, Dronkers et al. (1998) recently reported a fairly foctsed common area of tesion in aphasic patients with syntactic impairments in parsing. Dronkers $t$ t al. reconstructed and compared the area of full lesion overlap in nine patients with syntactic impairments in comprehension with a group of 12 patients who were aphasic but without syutactic comprehension problems. A straightlorward refation between structure and fundtion requires, in their view, that all patients with a specific cleficit shatre ote or mote lesions sites, and. crucially, all patients witlote this deffeit are not lesioned in loe idemilied sites (Dronkess et at, 1948). Following this eriterion, they identified the anterior portion of 


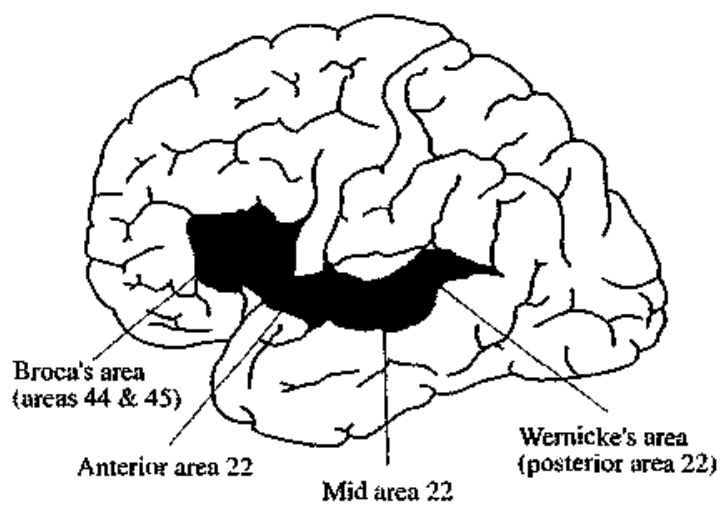

Fig. 9.6 Area of t00 per cent lesion overlap (in black) bn aphasic patients with a morphosyntactic processung deficit. The data are from the Dronkers et al, study (see texl). The numbers inchcate Brodmann areas.

the superior-temporal gyrus as the only area meeting their stringent criteria for assignment of function to structure (see Fig. 9.6). This area lies anterior to the primary atuditory cortex, and posterior to the temporal pole. It comprises part of Brodmann area 2 ?.

The anterior-temporal area is not classically assocjated with syntactic functions. The authors hypothesize that especially the reciprocal connections of this temporal lobe area to areas relevant for memory in parahippocampal, perirhinul, and hippocampal regions might explain its role in supporting 'specialized aspects of memory dedicated to linguistic structure' (p. 29). The classical Broca's area was found to be lesioned in eight of the nine patients with syntactic impairments, but also in three of the twelve patients without syntactic problems.

Although not directly isolating syntactic functions, data from a PET study' (Mazoyer at al. 1993) and a 4 Tesla fMRI study on sentence processing (Bavelier et $a l$. 1997) are compatible with the syntactic involvement of the anterior parts of the superior-temporal gyrus, although in these studies the temporal pole was clearly part of the activated area as well.

The findings in the Dronkers t al. study are clearly suggestive for a role of the leftunterior superior-temporal gyrus in the neural cincuitry for parsing. Despite its absence in the list of classical language areas, future brain-imaging research might be able to confirm the role of this area in syntactic processing. At the same time, it is unlikely that this area is the only ane with a syntactic iunction. The stringency of the criteria that were used in the Dronkers ' ' al. study almost certainly led to an underestimation of the number of areas involved in syntactic processing. Moreover, a closer inspection of the patients* imprimment profiles suggests that one camol exclade the possibility thit the impairments in the patients with the anterior-temporal lesions were not solely 
related to syntactic processing, but implicated other sentence-level jrocesses as wefl. The precise contribution of this area to syntactic processing is, therefore, yet to be determined.

Lesion data are also available on syntactic processing at the single-word level. This concerns lemma retrieval, more in particular the access to grammatical word-ctass information. Especially Caramazza and colleagues (Caramazza and Hillis 1991; Hillis and Caramazza 1995; Rapp and Caramazza 1997) have made some interesting claims on the basis of dissocistion patterns in neuropsychological patients with lesions in the left perisylvian cortex. On the basis of a few single-case studies, these atthors have clained that grammatical word-class information is linked to word-form information, and thus independently represented for orthographic and phonological word-form representations. They reported a patient with a parietal lesion who had a specific impairment in the oral reading of verbs, a patient with a frontotemporal lesion and a specific impairment in the written production of verbs (Carantzza and Hillis 1991), and a patient with left frontal and temporoparietal strokes who made far more errors on nouns than verbs in speech, but showed the opposite pattern in reading (Hillis and Caramazza 1995). These data led them to believe that orthographic and phonological form-level representations are organized by grammatical category, and that separate brain structures subserve the processing of verbs and nouns. The multimodal, formrelated representation of grammatical word-class is usually not assumed by psycholinguistic models on language production and language comprehension (see Chapters 4,5 , and 6 of this volume). Moreover, the number of cases are too few, and the reported lesions not focal enough to make any substantial claims about the brain areas involved.

The distinction between the processing of nouns and verbs, however, is supported by other neuropsychological evidence. One source of evidence comes from the general observation that fluent aphasic patients who tend to have more posterior (temporal) lesions usually have more difficulty naming nouns than verbs. Non-fluent Broca's aphasics who more often have a frontal lesion, show a stronger tendency for naming difficulties in verbs than nouns (Miceli et al. 1988). Damasio and Tranel (1993) propose on the basis of a number of cases they studied, that the processing of nouns is subserved by left anterior and midale temporal regions, whereas left frontal regions are crucially involyed in the processing of verbs. Minimally, these results lend support to the claim that neural representations for specific types of lemna information are differentially distributed within the left perisylvian cortex.

\subsubsection{Haemodynamic studies}

PET and IMRI studies on language have mainly focused on single-word processing. Only a very limited number of brain-imaging studies investigated sentence-level processes. Most of these studies looked at the activation patterns associated with sentence comprehension (Bavelicr et al. 1997; Caplan et al., 1998; Jast at al. 1996h, Mazoyer et al. 1993; Nichelli et al. 1995; Stowe ef al. 1994; Stromswold et al. 1996). Only one study (Indefrey et al. 1996) contained a sentente production component. Only one study presented the sentence materials auditorily (Mazoyer $a t$ al. 1993). In all other 
stusies, subjects were given written input. In several of the studies it is diflicult to disentalagle ativations due to syntactic processes from those related to sentence-level semantics and phonology. In some studjes this is not possible at all, since the designs of these studies did not aim at isolating syntactic operations from other sentence-level processes (Bavelier et al. 1997; Mazoyer ot al. 1993). However, jnasmuch as anything can be stid on the basis of these studies about areas that are crucial for parsing, the left inferior-frontal gyrus including Broca's area is reported in five studies (see Fig. 9.7). In contrast to what the lesion data seem to suggest, on the whole the recent brain-imaging atata are not incompatible with the classical picture of Broca's area involvement in syntactic processing.

Four studies manipulated the syntactic complexity of the presented sentence materials (Caplan et al. 1998; Just et al. 1996; Stowe et al. 1994; Stromswold et al. 1996). Stowe et al. had subjects read sentences that were presented word by word. Three types of sentences were used: (i) long, syntactically complex sentences; (ii) short sentences that were syntuctically ambiguous; (iii) short, unambiguous sentences. The subjects were instructed to read the sentences carefully and be prepared to answer questions about the sentences at the end of the scanning session. The regional cerebral blood tlow (rCBF) in these sentence conditions was compared with the rCBF in a resling condition in which subjects looked at an empty screen. Having a resting condition as the control stake is now known to be far from optimal, since the resting condition itself elicits a complex pattern of activations and deactivations that night affect the results of the subtraction (cf. Shulman et al. 1997). For the syntactically

\section{Lateral view}

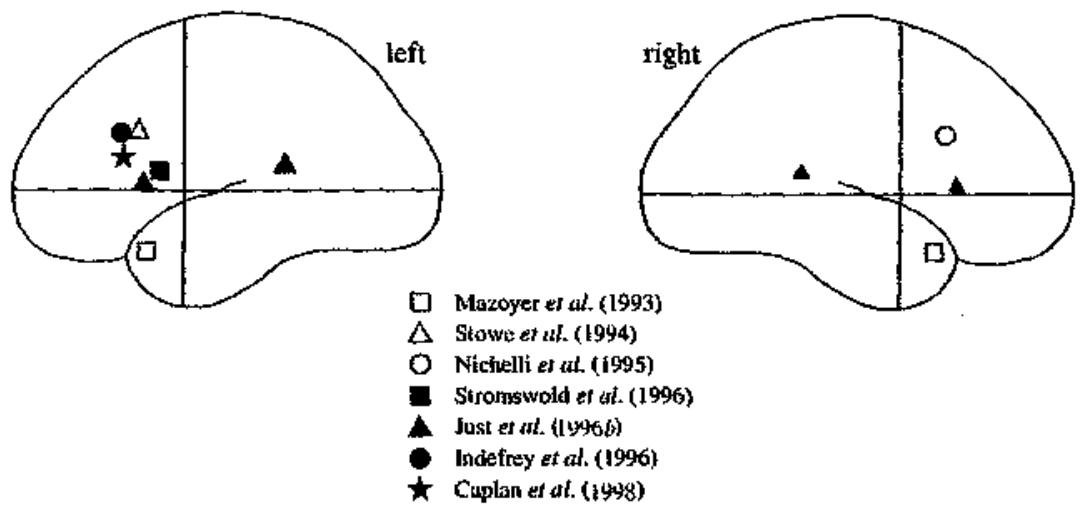

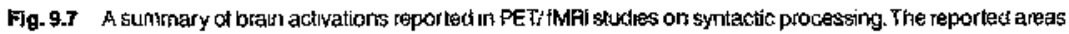

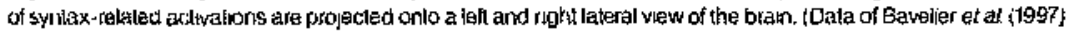
are not uncludet because of indivodual sunject variatwor) (Adapted from Hagoort and inciefrey (f997). Copyright 1997 Bohn. Statlau, van Łonghurn. reprinteal by permossbaz: 
complex sentences and for the ambiguous sentences the authors report a number of activations, including Broca's area on the border of the Brodmann areas (BA) 44 and 45. Activation in Broca"s area was also seen in a direct comparison between ambiguous and unambiguous sentences. The authors select this area among other areas of increased $\mathrm{rCBF}$ as the one that is most directly related to syntactic processing. Their argutment is that the activation in Broca's area fits best with the results of the classical lesion literuture on syntax-refevant areas. There clearly is some circulatrity involved in this line of reasoning, and, as we have seen, the lesion data are not at all conctusive about the role of Brocas area.

Stromswold et $a l$. (1996) contrasted sentences that were comparable in terms of their propositional content, but differed in syntactic complexity (e.g. The child spilled the juice that stained the rug versus The juice that the child spilled stainet the rig). Half of these sentences contained a semantic anomaly. The task of the subjects was to judge the acceptability of the sentences. A direct comparison between the structurally complex and the less complex sentences resulted in activation of Broca's area, more in particular the pars opercularis.

Caplan et al. (1998) repeated part of the design of the Stronswold et al. (1998) study, using the same sentence materials. In the repeated experiment, increased activation was again observed for the centre-embedded sentences in Broca's area, more specifically in the rostral part of the pars opercularis (BA 44). Additionally, medialfrontal activations were observed in the anterior cingulate gyrus and the immediately superior mediat-frontal gyrus. Although the exact same comparison for the identical sentences as in the Stromswold et al. study resulted in activation in the pars opercularis, the exact location of the rCBF increase was not identical to the Stromswold $c t a l$ study, but was higher and more anterior than in this earlier study. Factors related to subject variation between studies might account for this regional attivation difference within Broca's area.

A variation in syntactic complexity was also used in the fMRI study by Just et al. (1996b). In one condition subjects read sinuple active sentences (e.g. The reporter atucked the senator and abnitted the error), in a second condition they read sentences in which the subjects of the nuatrix clause and the subordistate clause were identical (e.g. The reporter that attaticd the semator admitted the erof). Finally the condition with the most complex sentences consisted of a matrix and a sisbordinate clisuse that had different grammatical subjects (The reporter that the schator attaked admitted th' eror'). These sentence were presented together with a probe question (e.g. The seporter attacked the senator, true or false?) that the subjects had to answer via a push-button response. The authors found an increasing number of activated voxels in rejation to the increase in syntactic complexity in both Broca's and Wernicke's area as well as in their right hemisphere homologues.

In contrast to the previous three studies, Nichellit at al. (1995) did not manipulate the syntactic complexity of their materials, but varied the task. la all conditions subject read the same story, that was presented visually, word by word. In the syntactic 
condition, subjects had to perform a syntactic errot-detection task by indicating when an occasional syntactic error had occurred. In the control condition, they had to detect words that were written in a different font. The syntactic error-detection task resulted in activation of the right inferior-frontal gyrus, the cingulate gyrus, and the left precentral gyrus.

Mazoyer of al. (1993) compared three conditions that had a syntactic component with two conditions that did not. These latter two conditions were a list of words and a story in Timil, a language unknown to the French monolingual speakers in this stady. Listeming to it story in Fremch, to a series of sentences consisting of pseudowords, and to semantically anomalous sentences all had in common the presence of a syntactic structure detectable for the French subjects. Subjects were required to listen attentively to the speech stimuli. Bilateral temporal pole activation was the prime candidate for being involved in syntactic processing, although the authors admit that other sentencelevel processes could also be responsible for this temporal pole activation.

Bavelier et al. (1997) performed an fMRI study at 4 tesla while subjects read sentences in a word by word presentation, where a word followed the presentation of the previous word after a delay of $600 \mathrm{mss}$. The activations due to sentence reading were conpared to the activations induced by consonant strings that were presented in the same way as the sentences. After each run, subjects were given a recognition memory task for the presented materials. Although the design of this study does not allow the isolation of syntactic processing, it nevertheless contains a number of relevant results. Overalt, activations were distributed throughout the left perisylvian cortex, including classical language areas (Broca's area, Wernicke's area, angular gyrus, supramarginal gyrus), but aiso left prefrontal areas and the left anterior-temporal lobe. At the individual subject level these activations were in several small, local, and distributed patches of cortex. Moreover, the precise pattern of activation varied quite substantially between individuals. For instance while Broca's area was activated in every subject, the precise localization of the activation with respect to the main sulci of Broca's area varied significantly between subjects. Similar between-subject variation in the distribution of language-relevant patches of cortex has been reported in electrical stimulation studies (e.g. Ojemann 1991). Bavelier et al. report that for a nonlanguage visual stimulation task the activated areas were much less patchy, containing more significantly activated contiguous voxels than the activations related to sentence reading. If the patchy pattern of activations and the substantial differences between subjects in the sentence reading condition of this study reflect an underlying difference between the neural organization of language and the neural organization of sensory provessing, this might well, at least in part, explain the lack of consistency in lesion and brain-imaging studies on higher sentence-level processing.

To date, the only study that had a grammatical encoding component next to a parsing component in its design is Indefrey $e^{t}$ al. $(1996 ; 1998)$. These authors required subjects to read sentences consisting of pseudowords and function words in German

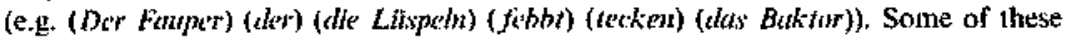


sentences contained a syntactic error (i.e. tecken, which does not agree in mumber with its preceding subject Faupr). In one condition, subjects had to detect this error (parsing) and to proviuce the sentence in its correct syntactic form (Der Fauper, der die Läspeln febht, techt das Bahtor). Thjs latter part requires grammatical encoding. In a second condition, subjects only judged the grammaticality of the input string white reading out the string as it was presented. A third condition required them to give phonological acceptability julgements for strings consisting of the same pseudowords and function words as before, but this time without syntactic strticture and will an occusional element that violated the phonotactic constraints of Germall. All these conditions were compared with a control condition in which subjects had to read out unstructured strings of pseudowords and function words. All syntactic conditions resulted in activation of the inferior frontal sulcus between (and partly including) the dorsal part of Broca's area and adjacent parts of the middle frontal gyrus (see Fig. 9.8). Both acceptability judgement tasks (syntactic and phonological) showed attivation ventral of Broca's area. in the pars orbitalis of the inferior frontal gyrus and the orbital gyrus, as well as in the right hemisphere homologte of Brocits area. These results suggest that the right hemisphere activation also found in some other studies (Just et $a$. I996h; Nichelli at $a l .1945$ ) might be due to the error detection component. The common syntactic processing component seems to be subserved more by the left frontal areas.

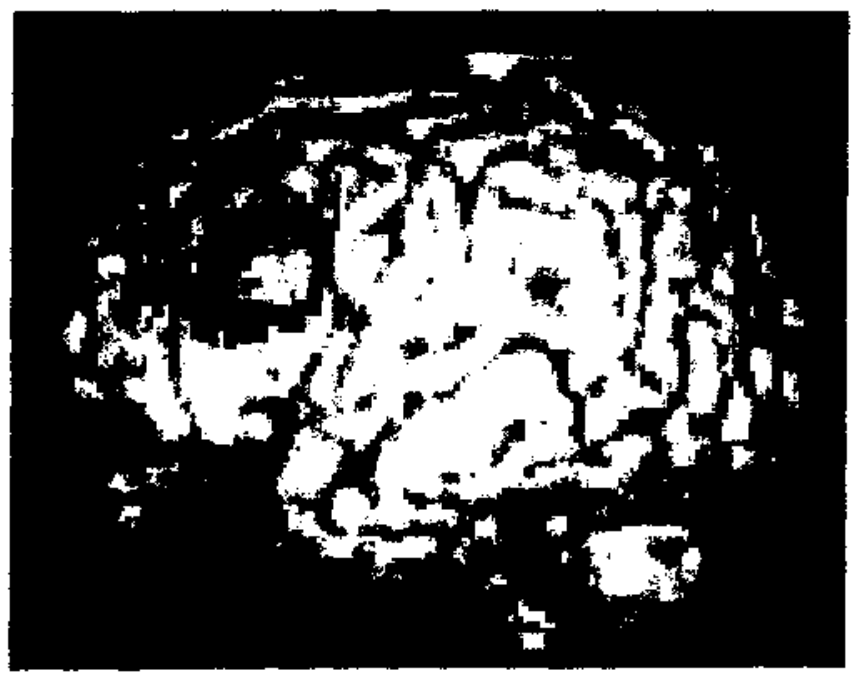

Fig. 9.8 The resulls of an SPM-Conjunction analysis projected onlo a lett laterai viw of the brain, separating the activaled areas for syntactic processing from areas active during non-syntactic tasks (1) e. psoudjowotd pronill kci.

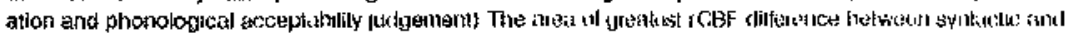
non-5yntactio lasks is shown in yalow. (Frotr hodefrey et al 1948). 


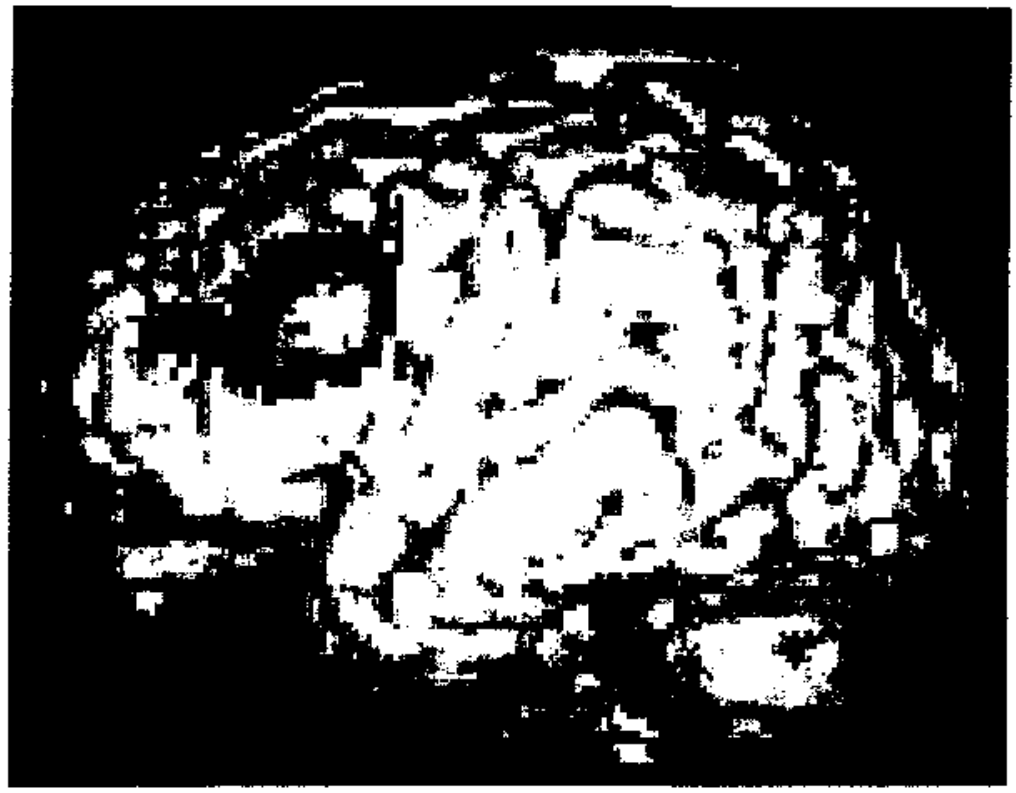

Figure 9.8 The results of an SPM-conjunction analysis projected onto a left lateral view of the brain, separating the activated areas for syntactic processing from azeas active during non-syntacttc tasks (i.e. pseudoword pronunciation and phonological acceptabilty judgement). The area of greatest rCBF difference between syntactic and non-syntactic tasks is shown in yeilow. (From Indefrey ef al. 1998). 


\subsubsection{Conclusion}

The combined evidence from tesion studies and haemodynamic studies results in a complicated picture. It is clearly impossible to single out one area that is dedicated to parsing and grammatical encoding operations. As was already discussed in the context of the ERP evidence, it is most likely that both parsing and granmatical encoding are based on the concerted action of a number of different brain areas with their own relative specialization. These relative specializations can be the memory requirements for establishing long-distance structural relations, the retrieval of a verb's argument structure and other lexical-syntactic information, the use of implicit knowledge about the structural constraints in a particular tanguage for grouping words into phrases, etc. All these operations are important ingredients of grammatical encoding and parsing. At the same time, they are clearly quite distinct and therefore are most likely not all subserved by one and the same area. Depending on which of these ingredients is manipulated in a particular study, different areas might be involved.

Some haemodynamic studies (Caplan et al. 1998; Just et al. 1996b; Stromswold et al. 1996) manipulated the syntactic complexity. Syntactic complexity effects are probably intimately linked to a memory system that is required for computations on and temporary storage of chunks of syntax-relevant information. Other studies manipulated the presence of syntactic cues. For instance, in the study of Mazoyer et al. (1993) listening to syntactically structured input was compared with listening to input that subjects could not interpret syntactically because they lacked the knowledge about the syntactic constraints of the language (Tamil). 'It is possible that the difference in results between this study and studies manipulating syntactic complexity is due to the fact that they capitalized on different central components of parsing. Similar differences probably contribate to the mixed results of lesion studies.

Altogether, it appears that a series of areas in the left perisylvian cortex contribute to syntactic processing, each with its own relative specialization. What these specinlizations are is to be determined in studies that single out the relevant syntactic variables.

In addition, there might well be (restricted) individual variation in the organization of the syntactic processing networks in the brain, adding to the complexity of the netral architecture of syntax (cf. Bavelier et al. 1997).

\subsection{What to conclude and where to go?}

The pisture emerging from the literature is that syntactic processing is subserved by a network of areats in the left perisylvian cortex, where each area has its own relative specializition. The detuiled disiribution of these areas presumably yaries between individuals to a larger extent than areas involved in sensori-motor functions. Broca"s area has been found to be especially sensitive to the processing load involved in symtuctic processing. It thus might be a crucial area for keeping the output of structurebuilding operations in a temporary buffer (working memory). At the same time one has 
to realize that Brocit's area probably consists of a number of morphometrically separate areas (Uylings et $a l$., Chapter 10 this volume). Broct's area might tlus be too cride a structure for the right grain size of function to structure mappings.

Temporal cortex, including anterior portions of the superior-temporal gyrus, are presumably involved in morpho-syntactic processing. The retrieval of lemma information such as word class (noun, verb, etc.) supposedly involves left frontal and left temporal regions (Damasio and Trenel 1993; Hillis and Caramazza 1995).

Electrophysiological data collected in the last few years have been most informative with respect to the cognitive architecture of the parser. These data atre compatible with a sentence processing model in which processing/representational uniqueness is attributed to syntactic versus other sentence-level processes. In addition, electrophysiological data provide relevant time-course information. ERP evidence suggests that lemma retrieval occurs within $300 \mathrm{~ms}$. Semantic and syntactic integration seems to occur within a time range between 300 and $600 \mathrm{~ms}$, where crosstalk between these processes is possible under certain conditions.

Progress in our understanding of the neural architecture of language is clearly handicapped by the lack of an animal model. Moreover, the individuat variation in the organization of the linguage cortex might be partly responsible for the lack of consistency in the results of lesion and brain-imaging studies. But in addition, the notions of sentence-level processing that were used in lesion and brain-inaging studies have often been too crude to allow real progress in our anderstanding of the neural architecture. Operational defimitions of sentence processing or of syntactic processing have not always been sufficiently informed by psycholingujstic processing models of language. This has sometimes linited the contribution of these studies to our understanding of the neural underpinning of language functions. For instance, in the case of syntactic processing, one has to make at least a distinction between grammatical encoding and parsing, and within each of these further distinctions have to be made between lemma retrieval, morpho-syntactic processing (i.e. the processing of the morphemes specifying the syntactic features, such as tense and number that are required by the syntactic context), the establishment of syntactic relations across word groups (e.g. long-distance dependencies), and the working memory involved in keeping the output of syntactic computations in temporary storage.

However, the good news is that models of languige production and conprehension have become detailed enough in the last decade to enable quite specific questions about the neural architecture of syntactic processing. Recent ERP studies have already contributed substantially to our understanding of the processing characteristics of syntactic processing. With the rapid developments in brain-imaging technology, the absence of an animal model for ianguage will be compensated through in rivo measurements of brain activity in the most syntactic animal of alt. Although a cognitive neuroscience of language is only beginning to see the dawn of tight. no doubt our current limited understanding of the neurocognition of linguage is the pretude to fundamental discoveries in the yetrs to come. 


\section{Acknowledgements}

We are thankful to the following colleagues for their comments on an earlier version of this chapter: Jos van Berkum, Kay Bock, David Caplan, Peter Indefrey, Gerard Kempen, Don Mitchell. Patrick O'Seaghdha, Mick Rugg, David Wilkins. We are grateful to Nina Dronkers for providing Fig. 9.6. 


\section{Notes}

1. Interestingly, but for reatsons that are not fally cleatr, a recent study failed to find at P600/SPS to the same agreement violations as in the Hatgoort et al. (1993) and Hagoort and Brown (1994) studies in sentences consisting of psendowords (Mïnte et al. 1997),

2. It is often seen ats a surprising finding that the latency of the $N 400$ is earlier than the latency of the P600/SPS. This surpise is based on the assumption that in the cognitive architecture of language comprehension the computation of a syntactic structure provides necessary input for the semantic interpretation process. The parser delivers candidate representations for semantic interpretation and for integration with prior discourse and expectations. However, is is argued by Bever et $a l$. (1998), this is by no means the only possibility. There are good teasons to claim that semantic analysis takes place before a full syntactic strueture is computed. According to Bever et $a l$. a correct syntactic structure is assigned only after an initial semantic analysis of the input. Although this is clearly a minority view and although there might be other reatsons for the observed latency difference between the N400 and the P600/SPS, the ERP evidence on the latency of 'semantic' and 'syntactic' integration effects is certainly not inconpatible with this proposal. 


\section{References}

Ainsworth-Darnell, K., Shuman, HI.. and Boland, J. (1998). Dissociating brain responses to syitactic and semantic anumalic: Evadence from event-related potentials. Jommal of Memory and Lamguage, 38, 112-30.

Altmann, G. T. M. (1988). Anbiguity, pursing strategies, and computational models. Langikge and Cognitine Processes, 3, 73.97.

Altuian, G. T. M. and Steedman. M. (1988). Interaction with context during human sentence proxessing. Connition, 30. 191. 238.

Basso, A., Lecours, A. R. Moraschini, S., and Vanier, M. (1985). Anatomoclinieal correlatious of the aphasias as defined through computerized tomography: Exceptions. Bitin and Lamgutuge. 26. 201--29.

Bates, E. and Goodıan. J. C. (1997). On the inseparability of gramnar and the lexicton: Evidence from acquisition, aphasta, and real-time processing. Languge amd Cognitiry Processes, 12, 507-84.

Bates, E., MeNew, S., MacWhinney, B., Devescovi, A., and Smith, S. (1982). Funtional consitruints on sentence processing: A cross-linguistic study. Corgnition, 11, 245-49.

Bavelier, D.. Corina, D., Jezzard, P., Padmanabhan, S., Ciark, V. P., Karui, A. « al. (1997).

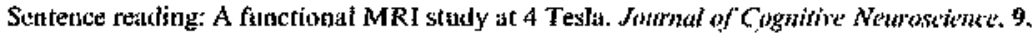
$664-86$.

Berkuın, J. J. A. van, Brown, C. M., and Hagoort, P. (1999). Early relerential contexl effects in sentence processing: Evidence fron event-retated brain potentials. Joumal of Hemm and Langthise. 40, (in press).

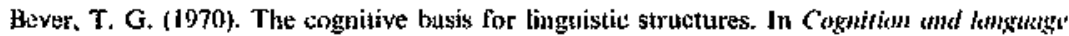
deweloponen (cd. J. R, Hayes), pp. 277-360. Wiley, New York.

Bcver, T. G., Sanz, M. and Townsend, D. J. (1998). The emperor's psychoilinguistics. Journat of Psycholinguistic Rexeurth. 27, 261-83.

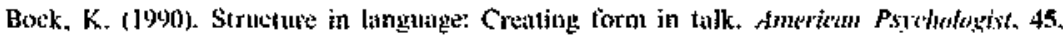
122136.

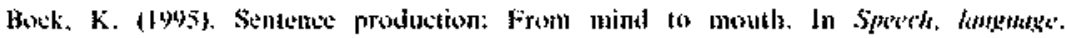
and commmication (eds J. Miller and P. Eimas), pp. J\&t 3!6. Acadtanic Press, San Diégo.

Bock. K. and Levitt. W. J. M. (1994). Languiate prodtction: Gramtnatical encoding. It)

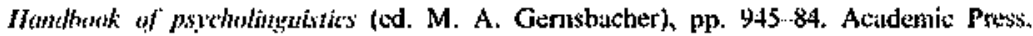
San Diegro.

Brown, C. M. and Hagoort, P. (1943). The processing nature of the N400: Evidente from

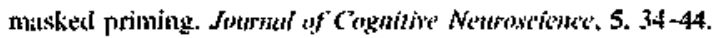

Brown, C. M., Hagnort, P., and ter Keurs, M. (1999). Electropluysiologicul signatures of vistal lexical processing. Joarnal of C'ognition' Nemostiente. 11 (In press).

Butterworth. B., Campbel]. R., and Howard, D. (1986). The uses of short-term ntentory: A

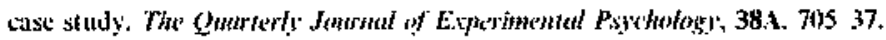


Caplan. D. (1987). Newolingaistits and lingmistic aphasiolegy" An introduction. Cambridge University Press.

Captan, D. and Waters, G, S. (1990). Short-term ntemory and langutge comprehension: A critical reviewof the neuropsycological Jiterature. In Netropsicholngical impaiments of short-temn monesty (eds G. Vallar and T. Shatlice). pp. 337 -89. Cumbridge Uriversity Press.

Caplan, D. and Waters, G. S. (1996). Syntactic processing in sentence compreinension under daskl-task conditions in atphasic patients. Language and Cognitive Proceswes, 11, 525-51.

Caplan. D. and Walers. G. S. (1909). Verbal working memory and scntence processing. Beharioral and Brain Sciknces. (In press)

Caplan, D., Baker, $C_{\text {, and }}$ Dethaut, F. (1985). Syntactic deferntinants of sentence comprehension in aphasia. C'ognition, 23, 11775.

Caplan. D., Hildebrandt. N., and Makris, N. (1996). Location of fesions in stroke patients with deficits in syntactic proessing in sentence comprelkension. Brim, If9, 933-49.

Caplan, D., Alpert, N., and Waters, G. S. (1998). Effects of symlactic structure and propositional number on patterns of regional cerethral blood tlow. Joumal of cognitive Nouroscience, 10, 541 52 .

Caramazza, A. and Hillis, A. E. (1991). Lexical organization of nouns and verbs in the britin. Natile, 349, 788-90.

Caramazza, A. and Zurif, E. B. (1976). Dissociation of algorithmic and hetristic processes in linguage comprehension: Evidence from aphasia. Bwin sha Language, 3, 572 82,

Comolly, J. F. and Philijs, N. A. (1994). Event-related potential components reflect phonological and semantic processing of the terminal words of spoken sentences. Jonmul of Coynitive Netwostience, 6, 256-66.

Coulson. S., King, J. W., and Kutas. M. (1998). Expect the unexpected: Event-related brain response to morphosyntaletic violations. Langhage and ('ignifive Processers. 13, 21-58.

Crain, S. and Steedman. M. (1985). On not being led up the garden path: The use of context by the psychologicat parser. In Natural longtwge parsing \{eds D. R. Dowly, L. Karttenen. and A. M. N. Zwicky), pp. 320-58. Cambridge Universify Press.

Damasio, A. R. and Trantl. D. (1993). Verbs and nouns are retrieved from separiate netral

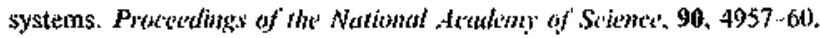

De Bleser. R. (1987). From agrammatism to paragrammatisn: Gutman aphasiological

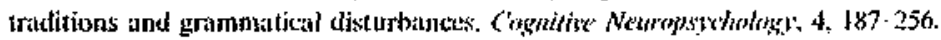

Dell, G. S. (1986). A spreading-activation theory of resricval in language production, Psychologicul Revien, 93, 283 321.

Dronkers, N. F.. Wilkins, D. P., Van Valin Jr, R. D., Redfern, B. B.. and Jatugur. J. J. (1998), Cortical areas unterlying the eomprehension of gramnuar. (Minuseript.)

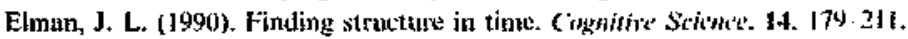

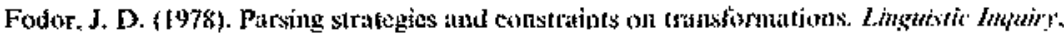
$9, \$ 27-73$.

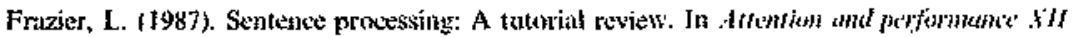
(ed. M. Coltheart). pp. 554 85. Esthaum, Lobdon.

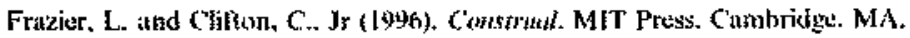


Frizier, L, and Rayner, K. (1982). Making and correcting errots during sentence соmprehension: Eye movements in the analysis of structurally ambiguous sentences. Cognitive Psytholog3: 14, 178-210.

Friederici, A. D. (1995). The time course of syntactic activation durinty language processing: A model based on neuropsychological and neurophysiological data. Brain and Langukge, 50. 259-81.

Friederici, A. D., Pfeifer, E., and Hahne. A. (1993). Event-related brain potentials during natural speech processing: Effects of semantic, morphological and syntactic violations. Cognitise Brain Research, 1, 183-92.

Friederici, A. D., Hathne, A., and Mecklinger, A. (1996). Temporal structure of syntactic parsing: Early and late event-related brain potential effects. Jettmol of Exporimomal Psychology: Leaning, Memory, and Cognition, 22, 1219-48.

Friederici, A. D. Hahne, A., and von Cramon, D. Y. (1998). First-pass versus second-pass parsing processes in a Wernicke's and a Brocals aphasic: Electrophysiological evidence tor il double dissociation. Bruin and Langiage, 62, 311-41.

Ganis, G., Kutas, M., and Sereno, M. I. (1996). The search for "common sense': An electrophysiological study of the comprehension of words and pictures in reading. Joumul of Cognitive Nomrosciencer, 8, 89--106.

Garnsey, S. M., Tanenhaus, M. K., and Chapman, R. M. (1989). Eyoked potentials and the study of sentence comprehension. Jotimal of Psycholinguistic Reseurch, 18, 51-60.

Garnsey, S. M., Pearlmutter, N. J., Myers, E., and Lotocky, M. A. (1997). The contribution of verb bias and plausibility to the comprehension of temporarily ambiguous verbs. Jommat of Mentory and Langutge, 37, 58-93.

Garrett, M. F. (1980), Levels of processing in sentence production. In Language production. Vol. 1 (ed. B. Butterworth), pp. 133-77. Academic Press, London.

Geschwind, N. (1965). Disconnection syndromes in animals and man. Brain, 88, 237-94, $585 \cdot 644$.

Gibson. E. (1998). Linguistic complexity: Locality of syntuctic âejendencies, Cognition, 68, 176.

Gunter, T. C.. Stowe, L. A., and Mulder, G. M. (1997). When syntax meets sentanties. Psichophlwiology, 34, 660-76.

Hagoort, P. and Brown, C. M. (1994). Brain responses to lexical ambiguity resolution and parsing. In Porspectives on sentence processing (eds C. Clilion Jr, L. Finivier, and K. Ruy'ner', pp. 45\%80. Erlbaum, NJ.

Hitgoort, P. and Brown, C. M. (1997), When syntax meets semantics: Who is doing what to

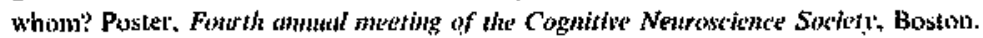

Hagooft. P. and Brown, C. M. Senantic and syntactic ERP effects of listening to spercl

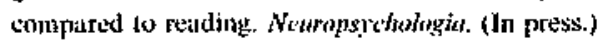

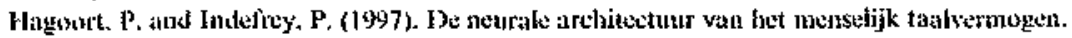

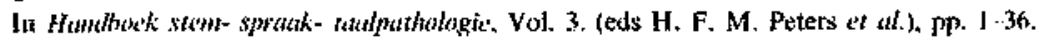
Bolıı, Stafleu, vun Loghum, Houten.

Hagoort, P., Brown, C. M., and Groothusten. J. (1993). The syntactic positive shift (SPS) at at ERP measure of syntactic processing. Langiage and Cognitrie Processes, B. 439-83. 
Hagoort, P., Brown, C. M., Vonk, W., and Hoeks, J. Symatic ambigaity eftects in coordination structures: ERP evidence. (Forthcoming.)

Hoschen, C. (1985). Agfammatism versus patagrammatism: A fictitiots opposition. In Agitammatism (ed. M.-L. Kean). pp. 207 48. Academic Press, San Diego.

Heitman, K. M. and Sclioles. R. 3. \{1976\}. The duture of comprehension errors in Broca's, cojklaction and Wernicke's aphasics. Cortex, 12. 25865.

Hillis, A. E. and Caranizza, A. (1995). Representation of grammaticat knowledge in the brain. Senmul of Cognitive Nomositinci, 7, 397-407.

Indefrey, P.. Hagown. P., Brown. C. M., Herzoي, H., and Seizz, R. J. (1996). Cortical acti-

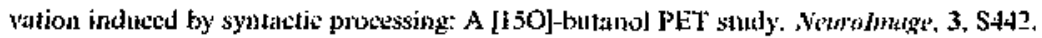

Indefrey, P., Hagoort, P., Brown. C. M., Herzog. H., and Seitz, R. J. (1998). Specific response of the left inferior frontal suleus to syntactic processing. (Manuscript)

Jackendoff, R+ (1997). The architecture of the langituge fituly . MIT Press. Cambidge. MA.

Just, M. A. and Carpenter. P. A. (1992). A capacity theory of comprebensions: Jutivideal differences in syntactic processing. Psychologtcal Roview, 99, 122-49.

Just, M. A., Carpenter, P. A., and Kelker, T. A. (1996a). The capacity theory of comprehension: New frontiers of evidence and arguments. Psivhological Rovicus. 103 . $773 \cdot 80$.

Just, M. A., Carpenter, P. A., Keller, T. A., Eddy. W. F., and Tlutllourt, K. R. (1946h). Brain activation modulated by sentence conoptehension. Science, 274, $114 \cdots 16$.

Kenpen, G. (1999). Grammatical performance in humau sentence production and compretetension. (Manuscript)

King, J. and Just, M. A. (194). Indivioual differences in syntactic processing: The role of working memory. Joumat of Hemers' art Languge, 30, 580-602.

King, J. W. and Kutas, M. (1995). Who did what and when? Using wort- and chatuse-level

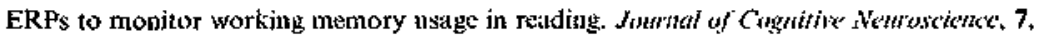
376-195.

King, J. W. and Kutas, M. (3998). Neural plasticity in the dymatnics of buman visuat word recognition. Nestarcionte Latiens, 244, 1.4.

Kbender, R. and Kulas. M. ( $(\mathcal{G}) 3$ ). Subjacency as a processing phenomenon. Langtatgk and C'ognitite Processses. 8. 573.633.

Kolk, H, and Heeselhen, C. (1992). Agranzmatism, paragrammatism and the managentent of

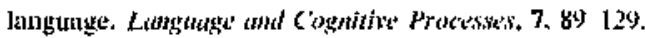

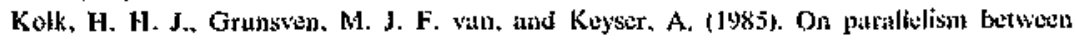
production and conprobension in agrammatism. In Agrammation (eal. M.-L. Kesat). pp. 165-206. Acadtentic Press, Satn Diegoro.

Kutas, M. (1997). Views on how the electrical activity that the brain generates retlects the functions of different language stractures. Psychophyiohogri, 34. 383-4\%.

Kutas, M. and Hillyard, S. A. (1980). Reading senseless sentences: Brain potentials raflect semantic anonitly. Sitionct. 207, 20135.

Kutas. M. and Van Petten, C. K. (1994). Psycholinguistics elettritied: Event-reiated braín

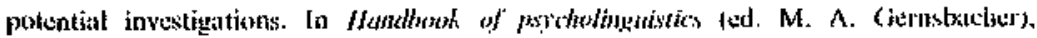

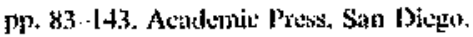


Levelt, W. J. M. (1989). Spesking: From intentien to artituhtion. Mil Press, Cambidge, MA.

Linebarger, M. C., Scluwartz, M. F., and Saffran, E. M. (1983). Sensitivity to gramnatical structure in so-called agranmatic aplusics. Cognition, 13, 361-92.

MacDonald, M. C.. Pearlmutter, N. J., and Seidenberg, M. S. (1994). Lexical mature of syntactic ambigatity resolution. Pspchological Revien, 10t, 676-703.

Martin, R. C. (1993). Short-term memory and sentence processing: Eviklence from neuropsychoisgy. Afmory and Cognition, 21, 176-83.

Mazoyer, B. M.. Tzourio, N., Frak, V., Syrow, A., Murayama, N., Levrier, O., et al. (1993). The cortical representation of speech. Jintmal of Cognitive Neturosciente, 5, 467-79.

McCleitand, J. L.. St. John. M.. and Taraban. R. (1989). Sentence comprehension: A paralle? distributed procassing approach. Lamginge and Cognitive Processes, 4, 287-335.

McKinnon, R. and Osterhout, L. (1996). Constraints on movement phenomena in sentence processing: Evidence from event-seJated brain potentials. Language and Cugnitive Procesises, 11, 495-523.

McRae, K., Spivey-Knowlton, M. J., and Tanenhaus, M. K. (1998). Modeling the intluence of thematic fit (and ofher constraints) in on-line sentence comprehension. Jownal of Me'mory aml Lungutere', 38, 283-312.

Metilinger. A, Schrisfers, H., Sleinbatuer, K., inul Friederici, A. D. (1995). Presessintk relative slatuses vaying on syntatic and semantic djmensions: An kablysis with eventrelated potentials. Mennory and Cugnition, 23, 477-94.

Miceli, G., Mazzucdi, A., Menn, L., and Goodglass, H. (19837. Contrusting cases of ltalian agranmatic aphasia without comprehension disorder. Brain and Language, 19, 65.97.

Micei, G., Silveri, M. C., Nocentini, U., and Caramazzi, A. (1988). Palterns of dissociation in comprehension and production of houns and verbs. Aphasiolog.', 2, 351-8.

Mitcheil, D. C. (1994). Sentence parsing. In Hondhook of prroholinguistics (ed. M. A. Gernsbacher), pp. 375-409. Academic Press, San Diego.

Mitchell, D. C. and Green, D. W. (1978). The effects of context and content on inmediate processing in reading. Quterterly Jonrnal of Experimentat Psycholugy, 30, 609-36.

Mitchell, D. C.. Cuetos, F. Corley, M. M. B., and Brysbaert, M. (1995). Exposure-based nodels of human parsing: Evidence for the use of course-grained (nonlexical) statisticont records. Jownal of Pxpcholinguistic Restewch, 24, 469.88.

Mohr. J., Pessín, M., Finkelstein, S., Funkenstejn, H., Duncan, G., and Davis, K. (1978). Brocu's aphasia: Pathological and cinical. Natologr, 28, 311-24.

Münte, T. F. alud Heinze, H. J. (1994). ERP negativities during syutuetic provessing of written words. In Cognitive elertrophysiofegy (eds H. J. Hejnze, T. F. Münte, autd G. R. Mangunt, pp. 211 38. Birkhatiser, Boston, MA.

Münte, T. F.. Heinze, H. J., and Mangun, G. R. (1993). Dissociation of bruin activity related

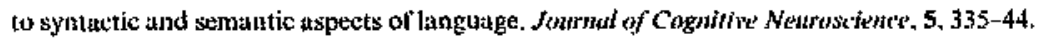

Münte, T, F., Matzke, M., und Johannes, S. (1997). Brain activity associaled with syultutic incongruities in words and pseudo-words. Jonrmal of Cognirive Nearostitencr. 9. 300-11.

Münte, T. F.. Fieioze, H. J., Matzke. M., Wieringa, B. M., and Johannes, S. (1498), Brain potentials and syntactic violations revisited: No evidence for specificity of the syntikite positive stifi. Nourupspreholengite, 36, 21726. 
Nespoulous, J.-L., Dordatin, M., Perron, C., Ski, B., Bub, D., Caplau, D., at al. (1992). Agrammatisn in sentence production without comprehension deficits: Reduced availability of syntactic structures andior gramnatical morplemes. A case study. Brain and Langutuge, 33. 273-95.

Nevitte. H. J., Nicol, J. L., Barss, A., Forster, K. I., and Garteâ, M. F. (t)yl). Syntuctically

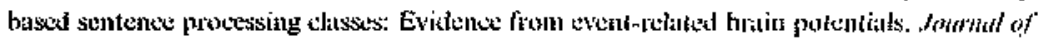
C'agnitive Neurascience', 3. 151-65.

Neville, H. J., Mils, D. L., and Lawson, D. S. (1992). Fractionating language; Different netural subsystems with difterent sensitive periods. Cerehral Cortex, 2, 24458.

Ni, W. Crain. S., and Shankweiler. D. (1996). Sidestepping garden paths: Assessing the contributions of synttx, semantics and platisibility in resoiving anbiguities. Language tmol Cognitive Processes, 1t, 283--334.

Nichelli, P., Grufmiln, J., Pietrini, P., Chark. K., Lec, K. Y., and Miletich, R. (1955). Where the brain appreciates the mortl of a story. Neion Repurt, 6, 3309-13.

Nobre, A. C. and MoCartlay, G. (1994). Language-related ERPs: Stajp distributions and modulations by word type and semantic priming. Soumal of Cognitive Nenrescioncer, 6 , 233-55.

Nobre, A. C., Allison, T., and McCarthy, G. (1994). Word recognition in the human inferior temporal tobe. Nistise, 372, 260-3.

Ojemann, G. (1991). Cortical organization of language and verbal memory based on introoperative investigations. Progress in Sensory Phintolog.1, 12, 193-210.

O'Seaghdha. P. G. O. (1997). Conjoint and dissociable eflects of sylutactic and semantic context. Journal of Exporimental Psychology: Lotsming. Memory. and Cognition, 23, $807-28$.

Ostarhout, L. (1997). On the brain response to syntactic anomaljes: Masipulations of word position and word class reveal individual diflerences. Brain and Langugge, 59, 494-522.

Osterhout, L. and Hagoort. P. (1999). A superficial resemblance doesn't necessarity mean you're part of the family: Counterarganents wo Coulson. King. and Kutas (lqus) in the

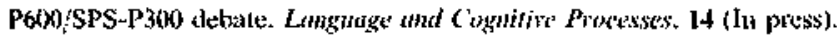

Osterhout, L. alid Holcomb. P. J. (19y2). Evint-relited hain potentials clicited by symtalcic

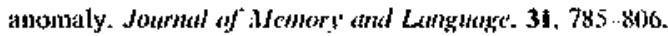

Osterhout, L. and Holcomb P. J. (1993). Event-Felated potentials and syntactic anomaly: Evidence of anomaly datection dutizly the gerception of contintous speech. Langutage and C'ognitive Prox'csises, 8, 413-38.

Osterhout, L. and Holcomb, P. J. (1995). Evelt-ielated porentials and language comprohen-

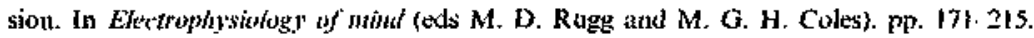
Oxtöd University Press.

Osterhout, L. and Mobley, L. A. (1995). Event-related botin potentiats elicited by faifure (o agree, fournal of Aftinury and Latrgutige, 34, 739 73 .

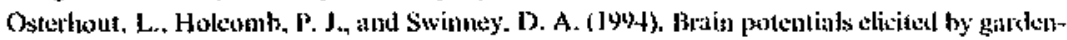
path sentenees: Evidence of the applieation of verb information during parsing. Jotomat of

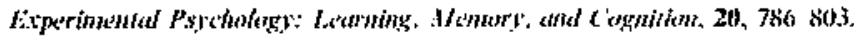


Osterhout, L., McKinnon, R., Bersick, M., and Corey, V. (1996). On the language-specifícity of the brain response to syntactic anomaties: Is the syntactic positive shift a member of the P300 fanily? Joumal of Cognitive Nenostience, 8, 507-26.

Osterhont, L.. Bersick, M., and McKinnon, R. (1997a), Brain potentials elicited by words: Wort letgth and frequency predict the latency of an early negativity. Biological

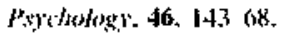

Osterhust, L., McLatughtin, J. and Bersick, M. (1997b). Event-related brain potentials and Jaman language. Thends in Cognitive Sciences, 1, 203-9.

Patel, A. D. Gibson, E., Ratner, J., Besson, M., and Holcomb. P. J. (1988). Processing syntactic relations in language and masic: An event-related potential study. Jownd of Cognitive Neturascience, 10, 717-33.

Praamstra, P., Meyer, A. S. and Levelt, W. J. M. (1994). Neurophysiologital manifestations of phonologicat processing: Latency variation of a negative ERP component timedocked to

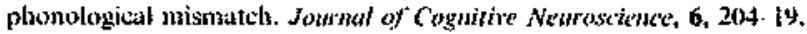

Pritchete, B. L. (1992). Grammatiol empetence and parsing performance. Unjversity of Chicago Press.

Pulvermiller, $F_{m}$ Lutzenberger. W., and Birbaumer, N. (1995). Electrocortical distinction of vocubulary types. Electroencephalography and Clinical Neupophystolog.1. 94. 357-70.

Rupp, B., and Caramazza, A. (1997). The modality-specific organization of granumatical entegories: Evidence from impnired spoken and written sentence production. Brain and Isingutuge, 56, 248-86.

Roclofs. A. (1992). A spreading-activation theory of Jemna retrieval ib speaking. Cogntion. 42, $107 \cdot 42$.

Roelofs, A. (1993). Testing a non-decompositional theory of lemma retrieval in speaking: Retricval of verbs. Coynition, 47, 59-87.

Rösler, F., Fricderici, A. D. Pülz, P., and Hakıe, A. (1993). Event-related brain potentials while encountering sennantic and syntactic constraint violations. Journal of Cognitive Nowasticinte, 3, 345-62.

Ru集, M, D. (1984a). Event-related potentials in phonological matelíg tasks. Brain and Lutigings, 23. 225 .44.

Ragg. M. D. (1984b). Event-related potentials and the phonological processing of words and nodt-words, Neroopsieholegia, 22, 642-7.

Rugg. M. D. and Barrett. S. E. (1987). Event-feiated potentials and the interaction between orthographic and phonodogical information in a rhyme-judgement task. Brum and Langutug, 32, 336-61.

Rugg. M. D. and Coles, M. G. H. (1945). The ERP and cogntive psychology: Conceptual issies. In Elevtrophysiology ef'mind: Event-retated brain potentials and cognitiom. (eds M. D. Rugg and M. G. H. Coles), pp. 27-39. Oxford University Press.

Schriefters. H., Fricuderiti. A. D., and Kanhn, K. (1995). The processing of locally anabiguons relative clauses in German. Joumal of Afomory and Lenguage, 34, 49)-520.

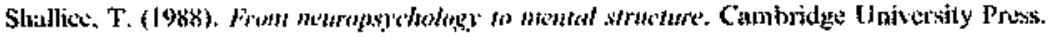

Shulnaan, (i. L., Cotbetta, M., Buckner, R. L., Raiclıle, M. E., Ficz, J. A., Miezin. F. M.. and

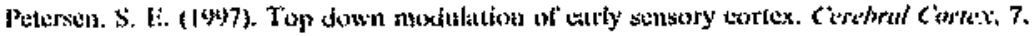
193 20). 
Stowe, L. A., Wijers, A. A., Willensen. A. T. M., Reuland, E., Paans, A. M. J., and Vatalbarg, W. (1994). PET-studies of language: An assessment of the reliability of the technigute. Jound of Pyncholinguistit Resetrih 23, 499-527.

Stromswold, K., Caplatu. D., Alpert, N., and Rauch, S. (1996). Localization of syntactic comprehension by positron emission tomography. Bhain and Lungutage, 52, 452-73.

Tabor, W. and Tanenhaus, M. K. (1998). Dynamic nodels of sentence processing. (Manuscript.)

Tunenbaus, M. K. and Trueswell, C. (1995). Sentence comprelzension. In Specth. langatige. and communication (eds J. L. Miller and P. D. Einlas), pjo. 217\%62. Acudenic Press, Sian Diego.

Tanenhaus, M. K., Spivey-Knowiton. M. J., and Hanna, J. E. in Arehiternits and merhamisms for langutge protessing (eds M. Crocker. M. Pickering. and C. Chifton). Cambridge (Universiiy Press, (In press.)

Trueswet, J. C., Tinenlunts, M. K., and Kello, C. (1493). Verb-specilic constraints in sentence processing; Separating eflects of lexical preference froni garden-paths. Joumat of Experinental Psychology: Learning, Manowy, and Cognition, 19. 528-53.

Vanier, M. and (aplan, D. ( I990). ('T"-scal cortelates of agrammatisn. Agromulatic aphasia.

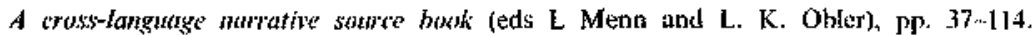
Benjasmins, Amsterdaji.

Von Slockert, T. R. and Bader, L. (1976). Some relations of grammar and lexieon in aphusia. Comex, 12, 49-60.

Vosse, T. and Kempen, G. (1999). Synlactic proxessing in humall sentence comprehenston: An inhibition-based parser with a texicalized grammar. (Manuscript.)

Wassenaar, M. Higoort, P., atrd Brown. C. M. (1997). Syntactic ERP effects in Brocit's aphasics with agrammatic comprebension. Brain and Languagt, 60, 6I-4.

Waters, G. S. and Caplan, D. (1996). The capacity theory of sentence comprehension: Critique of Just and Carpenter (1992). Psj'dhologictal Review, 103, 761-77?

Waters, G. S., Cajłan, D., and Hijdebrandt, N. (1987). Working numory and written sentence comprehension. In Attention (and performuzec $X / I$ (od. M. Coltheart), pp. 531 55 . Erlbaum, London.

Waters, G. S., Caplan, D., and Hildebrandt, N. (199)\}. On the structure of verbal STM and its functional role in sentence comprehenston: A case study. Cognitive Nenropsychologr: 8. $81-126$.

Wilimes, K. and Poeck, K. (1993). 'To what extent can aphaste syndromes be locatized? Brain. $116,1527-40$.

Zurif, E. B. (1998). The neurological organization of some aspects of sentente comprelsunsion. Joumat of Psycholingwisik Reseurch, 27, I\$1 90.

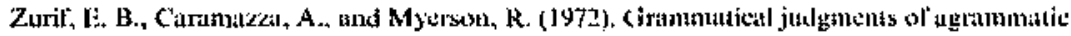
aphasics. Nourops!chologia, 10, $405 \cdot 17$. 